\title{
MIM3: Methodology of Innovation Management for Obtaining the Level 3 of I2MM
}

\author{
Emigdio Alfaro \\ CENTRUM Católica Graduate Business School, PUCP, Lima, Peru \\ Received December 2016; Revised May 2017; Accepted June 2017
}

\begin{abstract}
The purpose of the present study is to develop a methodological proposal for improving the management of the innovation maturity for obtaining the level 3 of the Integrated Innovation Maturity Model (I2MM), considering an integrated methodological approach which includes the good management practices of the following management areas: (a) strategic management, (b) project management, (c) innovation models and innovation methods, (d) standards for innovation management, (e) knowledge management, and (f) financial management. As a result, MIM3 (the Methodology of Innovation Management for obtaining the level 3 of the I2MM in the organizations) is presented.
\end{abstract}

Keywords: Innovation management, innovation maturity, methodology, project management, innovation standards, I2MM.

Reference to this paper should be made as follows: Alfaro, E. (2017). MIM3: Methodology of Innovation Management for Obtaining the Level 3 of I2MM. ICPE Public Enterprise Half-Yearly Journal, 23(1), 31-83.

\section{Introduction}

Innovation processes are commonly treated as creative processes and are centered on the technical aspects of the creation of the products, which are very important for the majority of innovation experts and practitioners; however, those creative processes are neither the unique nor the most important processes for obtaining the expected organizational goals. The most important aspect of the innovation processes must be the value generation in the organizations in which those processes will be developed. Diverse issues related to strategic management, project management, standardization of the innovation processes, knowledge management, and financial management are not considered with the point of view which is focused on the creativity, and there was not found a methodology with integrates the diverse parts for solving the described issues with the consequent delays in the adoption and the implementation of good practices of the innovation management which would improve the accomplishment 
of goals of the organizations. All the mentioned points of view were integrated in MIM3, a proposal for Methodology of Innovation Management for obtaining the level 3 of the I2MM, which constitutes the purpose of this study.

The proposed MIM3 methodology integrates the generation of ideas of innovative projects in a manner which is aligned with the strategic planning of the organizations in accordance with the organizational purposes and goals. MIM3 also includes the knowledge areas of the project management according to Project Management Body of Knowledge (PMBOK) of the Project Management Institute (PMI) and the use of the Critical Chain with the processes of innovation models and innovation methods, considering the good practices of the standards of innovation management. Additionally, MIM3 includes the yellow pages of the knowledge management and the evaluation of the value generation of the innovative projects with a procedure based on MEVGIT, which is also based on free cash flow, total cost of ownership, and the direct costing.

\section{Background of the Problem}

The issues related to the innovation management in the organizations are very diverse and are commonly treated without a holistic focus, being creativity the main associated focus, leaving aside the need to take into account the focus on the value generation for the organization, which must be the most important focus of the organization. The common issues related to the innovation processes of the organizations are the following:

1. The lack of integration of the innovation processes to the strategic planning of the organizations. The strategic plans don't include the innovation processes joint with the strategic, main or support processes or areas. In respect, Dougherty and Hardy (1996) explained that the two types of problems which are associated with innovation are the following: (a) those affecting a particular project and (b) those affecting the organizational context (p. 1121). Van de Ven (1986) also indicated that "the context of an innovation points to the strategic problem of institutional leadership" (p. 591). Additionally, in a comparison of some European countries (Austria, Bulgaria, Spain, Romania, Portugal, Poland, Czech Republic, Netherlands, Hungary, Slovakia, Sweden, and Greece), Robinson and Stubberud (2011) indicated the following issues:

A. No need to innovate due to prior innovation: (a) between $0.84 \%$ (Netherlands) and $23.68 \%$ (Greece) in small firms (between 10 and 49 workers), (b) between $0.88 \%$ (Netherlands) and $19.17 \%$ (Greece) in medium firms (between 50 and 249 workers), and (c) between 1.69\% (Netherlands) and $37.21 \%$ (Greece) in large firms (250 or more). In the cases of Sweden and Slovakia, neither small, nor medium, nor large firms indicated occurrences. 
B. No need to innovate because no demand for innovation: (a) between $0.99 \%$ (Netherlands) and 30.66\% (Greece) in small firms, (b) between 1.20\% (Netherlands) and 22.50\% (Greece) in medium firms, and (c) between $1.99 \%$ (Netherlands) and $28.84 \%$ (Greece) in large firms. In the cases of Sweden and Slovakia, neither small, nor medium, nor large firms indicated occurrences.

This lack of integration of the innovation processes into the strategic planning of the organizations affected the innovative projects and the organizations in which the innovative projects were developed; due to that, the projects did not generate value for the organizations in many cases, and the continuous loss of value would affect seriously the organizational processes and the business continuity, depending on the market conditions.

2. The innovation processes obtained good new products (goods or services, or both); however, the solution didn't include the complete business model to which the innovative product would be a part of, and as a consequence, the innovation failed. It is common for the focus to be on the intrinsic product and not on the business model as a whole, and due to that, some parts of the business model fail and the innovative project fails as a consequence. This situation could be presented in the production of goods, the production of services, and the production of goods and services, depending on the type of economic sector.

3. The innovation processes obtained good new products; however, the personnel of the organization don't know which needs of which users will be satisfied or which problems will be solved with the new products, or the costs are very high. In diverse situations, the areas of innovation developed many new ideas of products without a focus on the value generation for none of the stakeholders of the organization, situation which causes more delays and expenses to the diverse processes of the organization. It is common to find that the people of the diverse areas inside the same organization do not agree about how the products generate value for the consumers or the clients and do not agree about the perception of the stakeholders related to the products of the organizations.

4. The project management of the innovative projects has the common type of problems which are presented in the diverse types of projects, related to: integration management, scope management, time management, cost management, quality management, human resources management, communications management, risk management, acquisitions management, and stakeholders management. In respect, to the question about the common problems of the firms with their innovation initiatives, Gooffrey Moore answered in an interview (Davidson \& Leavy, 2007) that "the biggest challenge comes from the life cycle of innovation, which calls for different management 
focus at different stages" (p. 4). Dougherty and Hardy (1996) also explained that "when project-level problems are solved across multiple innovations and multiple stages simultaneously, sustained innovation can occur" (p. 1121). Additionally, in a comparison of some European countries (Austria, Bulgaria, Spain, Romania, Portugal, Poland, Czech Republic, Netherlands, Hungary, Slovakia, Sweden, and Greece), Robinson and Stubberud (2011) indicated the following issues:

A. The innovation activity is seriously delayed: (a) between $9.5 \%$ (Spain) and $33.42 \%$ (Netherlands) in small firms, (b) between $12.81 \%$ (Spain) and $39.16 \%$ (Sweden) in medium firms, and (c) between $17.73 \%$ (Spain) and $51.05 \%$ (Sweden) in large firms. In the cases of Austria and Portugal, neither small, nor medium, nor large firms indicated occurrences.

B. Lack of funds within the enterprise or enterprise group: (a) between $9.24 \%$ (Netherlands) and 34.19\% (Romania) in small firms, (b) between 6.4\% (Netherlands) and 27.27\% (Poland) in medium firms, and (c) between $8.03 \%$ (Portugal) and $32.09 \%$ (Greece) in large firms. In the case of Sweden, neither medium nor large firms indicated occurrences.

C. Lack of finance from sources outside the enterprise: (a) between $5.43 \%$ (Netherlands) and 32.60\% (Romania) in small firms, (b) between 3.00\% (Netherlands) and 28.49\% (Portugal) in medium firms, and (c) between $3.22 \%$ (Netherlands) and $28.75 \%$ (Portugal) in large firms. In the case of Sweden, neither small, nor medium, nor large firms indicated occurrences.

D. Innovation costs are too high: (a) between 6.18\% (Greece) and $40 \%$ (Portugal) in small firms, (b) between 5.88\% (Netherlands) and 28.63\% (Spain) in medium firms, and (c) between 6.75\% (Netherlands) and 26.09\% (Romania) in large firms. In the case of Sweden, neither small, nor medium, nor large firms indicated occurrences.

E. Lack of qualified personnel: (a) between $6.6 \%$ (Netherlands) and $24.95 \%$ (Greece) in small firms, (b) between 6.93\% (Poland) and 27.50\% (Greece) in medium firms, and (c) between 4.28\% (Poland) and 40.47\% (Greece) in large firms. In the case of Sweden, neither small, nor medium, nor large firms indicated occurrences.

F. Difficulty finding cooperation partners for innovation: (a) between $1.80 \%$ (Netherlands) and 16.02\% (Greece) in small firms, (b) between 1.99\% (Czech Republic) and 28.85\% (Greece) in medium firms, and (c) between $0.55 \%$ (Hungary) and $38.14 \%$ (Greece) in large firms. In the case of Sweden, neither small, nor medium, nor large firms indicated occurrences. 
5. For the innovation processes, the creative processes and not the value generations of the organizations are prioritized. Depending of the type of organization (profit or non-for-profit organization), the value generation would be measured by money (firms or profit organizations) or by the expected results of benefits to the target population (non-for-profit organizations). In the value generation, commonly the total costs of ownership (TCO) of the innovative projects are not well calculated, and due to that, the innovative projects resulted in failures. If only after the acquisition of the goods and services, the managers take into account the costs of the support and the maintenance of the results of the innovative project, then it is probably that the reduction of value with that project appears evident.

6. The lack of regulatory framework for norming the innovation processes in the organization. There is not a regulatory framework which norms the following aspects: incentives (monetary or non-monetary), roles, committees, intellectual property rights, participation of the benefits after the new products are developed or put in the market, accounting processes for registering the innovation processes and products, etc. Also, the individual contracts commonly did not include anything about the innovation processes or innovative products that the personnel must realize, without the cases of people who have contracts for innovative or intellectual processes or areas, such as: research and development areas in industries, research areas in universities, etc.

7. The lack of motivation or incentives to the personnel of the organization, for proposing new ideas or innovative projects. Commonly, the ideas, the reports or another intellectual production of the personnel are taken by the bosses or coworkers, and additionally, the propositions of new ideas or innovative projects don't result in awards or recognition for the innovative people. If the people are not recognized or rewarded, and the risk of plagiarism is present, then the people will not be motivated to propose new ideas. With regards to the question related to the single most intractable problem with their innovation initiatives, Gooffrey Moore answered in an interview (Davidson \& Leavy, 2007) that "the core of the challenge is the internal competition for execution-oriented leaders. These people are key to keeping the engine of a mature business running, consistently squeezing out incremental growth from an increasingly challenging set of options" (p. 4). It is important to recognize that the investment in technologies for innovation could be only expenses if the people are not motivated to use those technologies for developing innovations.

8. The lack of time and opportunities for the personnel of the organization, for presenting new ideas or innovative projects. The personnel of the organization are commonly fighting the daily labors and don't have time in the regular labor time for the innovative processes or the creation of new ideas or products. In this sense, Van de Ven (1986) explained that "there is the human problem of 
managing attention because people and their organization are largely designed to focus on, harvest, and protect existing practices, rather than pay attention to developing new ideas" (p. 591). Many bosses limit the opportunities of the personnel of the organization for presenting new ideas or innovative projects to avoid that their subordinated personnel shine in the eyes of the high-level management or the board of directors, and in the future, will convert them in candidates for the labor positions of the bosses.

9. The lack of training and competencies (knowledge, abilities, and attitudes) for creating and developing new ideas or innovative projects. Some workers of the organization, commonly are not sufficiently trained for creating and developing new ideas or innovative projects, related to the economic sector or the market of the organization; also, the managers or the board of directors don't promote the training of the personnel through the human resources area, due to the fact that they think that the training is not an investment, on the contrary, they think that the training is an unnecessary expense in many cases, and due to that the personnel could leave the organization in the short term.

10. The lack of investment or expenses on infrastructure, equipment and other resources, for prototyping and testing the new ideas. The elaboration of prototypes requires investment or expenses in infrastructure, equipment and other resources (materials, personnel, and investment), which commonly is promised but not budgeted or simply is not budgeted or is not sufficiently assigned. It is important to indicate that in many countries there are private or public competencies (national or international) of innovative projects, with the corresponding awards, financial coverage or financial loans with very low interest rates; however, the workers of many organizations don't know about them and consequently don't participate and don't obtain the funds which are necessary for the development of the innovative projects. In this sense, in a comparison of some European countries (Austria, Bulgaria, Spain, Romania, Portugal, Poland, Czech Republic, Netherlands, Hungary, Slovakia, Sweden, and Greece), Robinson and Stubberud (2011) explained that one of the problems for improving the innovations of the firms, is the lack of information on technology: (a) between 1.95\% (Slovakia) and 29.96\% (Greece) in small firms, (b) between 1.02\% (Slovakia) and 30.83\% (Greece) in medium firms, and (c) between $0.83 \%$ (Hungary) and $56.74 \%$ (Greece) in large firms. In the case of Sweden, neither small, nor medium, nor large firms indicated occurrences.

11. Absence of a collaborative culture which permits the synergies among the workers of the organization for improving the ideas of innovative projects. Each worker wants to shine by herself or himself, and doesn't want to collaborate with coworkers for improving the ideas of innovative projects. In this sense, Choudhury (2013) explained that "although organizations increasingly recognize knowledge as a key source of competitive advantage, one of the challenges of 
knowledge management is that of getting people to share their knowledge" ( $p$. 38). Van de Ven (1986) also indicated that "there is the structural problem of managing part-whole relationships, which emerges from the proliferation of ideas, people and transactions as an innovation develops over time" (p. 591). The human resources departments have a very hard challenge for improving the collaborative culture for stimulating the innovation in the organizations.

12. Many workers of the organizations feel that the standardized norms and procedures limit them for introducing new ideas of innovative projects. In this sense, many workers are fearful of realizing actions out of the standardized norms and procedures for avoiding the future and negative reactions of their bosses who commonly act in a negative way in front of the presentation of new ideas, considering them as a waste of time, effort, and money.

13. The innovation processes are developed without the validation of the satisfaction of the needs to the early adopters or consumers with similar characteristics, with the innovative products (goods, services, or both). In many cases, the organizations fail in the innovation processes; due to that their high investment is converted in a waste of money and time - nevertheless, meanwhile the innovation processes have occurred, validations of the satisfaction of needs of the potential consumers were not done and the products must be re-elaborated continuously, with excessive additional costs and steps in comparison with the normal innovation processes. In this sense, in a comparison of some European countries (Austria, Bulgaria, Spain, Romania, Portugal, Poland, Czech Republic, Netherlands, Hungary, Slovakia, Sweden, and Greece), Robinson and Stubberud (2011) explained some problems with the innovation activities as follows:

A. The innovation activity is abandoned at the concept stage in the following ranges: (a) between 2.94\% (Bulgaria) and 33.01\% (Greece) in small firms, (b) between 2.55\% (Bulgaria) and 40.47\% (Sweden) in medium firms, and (c) between 1.99\% (Bulgaria) and 63.6\% (Sweden) in large firms. In the case of Austria, neither small, nor medium, nor large firms indicated occurrences.

B. The innovation activity is abandoned after it began: (a) between $4.79 \%$ (Bulgaria) and 20.94\% (Slovakia) in small firms, (b) between 2.81\% (Bulgaria) and 19.36\% (Netherlands) in medium firms, and (c) between $3.64 \%$ (Bulgaria) and $46.86 \%$ (Sweden) in large firms. In the case of Austria, neither small, nor medium, nor large firms indicated occurrences.

14. The introduction of the innovative products into the market doesn't have a previous validation with early adopters with similar characteristics to the target consumers. As a result, the consumers of the target market don't buy 
the innovative product and the organization fails in its introduction, with the corresponding waste of time, effort, and money. In this sense, Dougherty and Hardy (1996) indicated that "at the level of the particular product, problems include positioning the product strategically in the market, development production, marketing, and sales, securing expertise, managing external relations (Kazanjian, 1988), understanding new markets (Cooper, 1983; Leonard-Barton, 1991), forming multifunctional teams and sharing knowledge (Ancona \& Caldwell, 1990; Dougherly, 1992), and evaluating progress (Griffin \& Page, 1993)" (p. 1121). Additionally, in a comparison of some European countries (Austria, Bulgaria, Spain, Romania, Portugal, Poland, Czech Republic, Netherlands, Hungary, Slovakia, Sweden, and Greece), Robinson and Stubberud (2011) explained the following issues:

A. Lack of information on the markets: (a) between 1.72\% (Slovakia) and $35.57 \%$ (Greece) in small firms, (b) between 1.42\% (Slovakia) and 31.88\% (Greece) in medium firms, and (c) between 2.22\% (Hungary) and 52.09\% (Greece) in large firms. In the case of Sweden, neither medium nor large firms indicated occurrences.

B. Markets dominated by established enterprises: (a) between $5.25 \%$ (Netherlands) and 23.81\% (Greece) in small firms, (b) between 3.68\% (Netherlands) and 24.69\% (Greece) in medium firms, and (c) between $3.88 \%$ (Hungary) and $27.44 \%$ (Greece) in large firms. In the case of Sweden, neither small nor medium firms indicated occurrences.

C. Uncertain demand for innovative goods or services: (a) between $3.73 \%$ (Netherlands) and 23.41\% (Greece) in small firms, (b) between 4.04\% (Netherlands) and 20\% (Greece) in medium firms, and (c) between 6.13\% (Netherlands) and 33.49\% (Greece) in large firms. In the case of Sweden, neither small, nor medium, nor large firms indicated occurrences.

\section{Problem Statement}

Based on the literature review performed, there was not found a methodological proposal for improving the innovation maturity of the organizations to the level 3 of $\mathrm{I} 2 \mathrm{MM}$, integrating the good practices of strategic management, project management, innovation management, knowledge management, and financial management, according to the processes of the value generation of the organizations. This situation delays the adoption and the implementation of good practices of the innovation management, which would improve the accomplishment of goals in the organizations. 


\section{Purpose of the Study}

To develop a methodological proposal for improving the management of the innovation maturity until the level 3 of the I2MM, considering an integrated approach which includes the good practices of strategic management, project management, innovation management, knowledge management, and financial management.

\section{Theoretical Framework}

The main topics for understanding the innovation management and the methodological proposal MIM3 are the following:

Table 1

Some Topics of the Theoretical Framework of Innovation Management

\begin{tabular}{|c|c|}
\hline Topic & Details of the Topic \\
\hline Foundations of Innovation & Concepts, parts, and types of innovation \\
\hline $\begin{array}{l}\text { Innovation models and innovation } \\
\text { management processes }\end{array}$ & $\begin{array}{l}\text { (a) The Creative Process, (b) Classic Process } \\
\text { of Staging and Gating of an Innovation } \\
\text { Project, (c) Proof of Concept and Pilot } \\
\text { Studies, (d) Integrated Innovation Maturity } \\
\text { Model (I2MM), (e) Seeking Solutions } \\
\text { Approach, (f) 3-Stage Roadmap towards } \\
\text { becoming a sustainable organization, (g) } \\
\text { Design Thinking, (h) Goodyear's business } \\
\text { model innovation process, (i) FastWorks } \\
\text { Framework, (j) InnoCamp Model, (k) Lean } \\
\text { Innovation Model, and (l) Lean Startup }\end{array}$ \\
\hline
\end{tabular}

Standards related to the innovation management

(a) UNE 166002:2014 R\&D\&I Management: R\&D\&I management system requirements, (b) ONR CEN/TS 16555-1 Innovation Management - Part 1: Innovation Management System (prCEN/ TS 16555-1:2012), (c) ISO/TC 279 Innovation management, and (d) BS 70001:2008 Design Management Systems - Part 1: Guide to Managing Innovation

Project Management Frameworks and (a) Project Management Body of Methodologies Knowledge and (b) Critical Chain

Yellow pages of Knowledge Definition and components of the yellow Management pages of knowledge management

Financial Criteria for the evaluation of (a) Free Cash Flow, (b) Direct Costing, (c) Innovation Management Total Cost of Ownership, and (d) MEVGIT 


\section{Foundations of Innovation}

According to Ahmed, Shepherd, Ramos, and Ramos (2012), the innovation includes two parts: (a) the generation of an idea or invention, and (b) the successful commercialization of that idea or invention; in other words: innovation = invention + level of use (p. 5). Ahmed, Shepherd, Ramos, and Ramos (2012) also indicated that the innovation could be classified as follows: social innovation, strategic innovation, philosophic innovation, process innovation, product innovation, and politics innovation. Additionally, British Standards (2008) defined innovation as follows:

1. As ideas, innovation is the "successful exploitation of new ideas" (p. 9).

2. As a process, innovation is the "introduction of changes that are significant departures from the usual way of doing things" (p. 9).

3. As a product, innovation is the "transformation of an idea into a novel product, operational process or new service" (p. 9).

4. As techniques or materials, innovation is the "employment of design or construction techniques, or materials, that do not have a proven history of performance or are not covered by an organization's current practice" (p. 9).

British Standards (2008) also defined the innovation management system as follows: "formal infrastructure encompassing objectives, strategies and processes, organizational structures and values by which an organization administers innovation" (p. 10). As can be appreciated, the innovation management is cross-sectional to the diverse processes or areas in the organizations, and must be developed taking into account the diverse related topics.

\section{Innovation Models and Innovation Management Processes}

The literature review highlighted the existence of diverse innovation models and diverse innovation management processes. In this sense, O`Raghallaigh, Sammon, and Murphy (2011) classified the innovation models based on their following characteristics:

1. Timeframe: (a) 1950s to late 1970s, (b) Mid-1970s to mid-1980s, and (c) Mid1980s-present.

2. Generations (model exemplars): (a) First Generation (Technology-Push), (b) Second Generation (Market-Pull), (c) Third Generation (Chain-Linked), (d) Fourth Generation (Cooperative R\&D), and (e) Fifth Generation (Systems Integration and Networking: SIN).

3. R\&D: (a) An increase in R\&D results in more innovation-oriented output, (b) Emphasizes how R\&D interacts with market forces, and (c) Emphasizes cooperative R\&D and the links between independent agents.

4. Knowledge source: (a) Internal scientific research is the main knowledge 
source, (b) Internal scientific research as well as knowledge acquired from other (mainly) internal sources, and (c) Knowledge acquired from both internal and external sources.

5. Market forces: (a) For technology-push the market forces are largely ignored. For market-pull the market forces direct the R\&D investment, (b) Market forces interact with R\&D decision-making, and (c) Horizontal and vertical alliances respond to market changes.

Some innovation models or innovation management processes, which were found in the literature, were the following: (a) the creative process, (b) the classic process of staging and gating of an innovation project, (c) the proof of concept and pilot studies, (d) the Integrated Innovation Maturity Model (I2MM), (e) the Seeking Solutions approach, (f) 3-Stage Roadmap towards becoming a sustainable organization, (g) Design Thinking, (h) Goodyear's business model innovation process, (i) FastWorks Framework, (j) InnoCamp Model, (k) Lean Innovation Model, and (l) Lean Startup. These innovation models of innovation management processes are explained in the following paragraphs.

About the creative process, Gibney (1998) indicated that the majority of psychologists used different terms to identify the phases of the creative processes, and that this process can be broken into the following five stages:

(a) Stage One: Immersion,

(b) Stage Two: Incubation,

(c) Stage Three: Insight,

(d) Stage Four: Evaluation,

(e) Stage Five: Elaboration.

With regards to to the classic process of staging and gating of an innovation project, Cohendet and Simon $(2015$, p. 9) indicated that the classic process of staging and gating of an innovation project has the following steps:

(a) Idea generation,

(b) Building business case,

(c) Development,

(d) Testing and valuation,

(e) Launch.

Cohendet and Simon (2015) also indicated that idea generation must be joined to the knowledge management and the innovation process, with coupling mechanisms, such as: "communities, boundary spanners, boundary objects, knowledge brokers, knowledge management platforms, modularity, etc." (p. 10). In the described innovation processes, the lack of inclusion of the alignment to the strategic objectives of the strategic plan, and the lack of inclusion of financial aspects are critical, because in the case of firms, the value generation is measured mainly by the financial value generation. 
Thabane, Ma, Chu, Cheng, Ismalia, Ríos, Robson, Thabane, Giangregorio, and Goldsmith (2010) explained that a proof-of-concept (PoC) study is "a clinical trial carried out to determine if a treatment (drug) is biologically active or inactive (Doughterty \& Hardy, 1996). PoC studies usually use surrogate markers and endpoints" (p. 3). Newfoundland Labrador (n. d.) also explained that a proof of concept is "the delivery of a working system to prove that the technology works and functions as intended" (p. 7) and that "it is usually small and may or may not include all functionality; instead, it refers to a partial solution that involves a relatively small number of users" (p. 7). Finally, Newfoundland Labrador (n. d.) indicated that "once complete, the PoC should be dismantled and considered complete after the results have been documented" (p. 7). The proof of concept is a basic step for developing the innovations, overall for avoiding the possible failures due to that it is better to fail in the earliest phases for reducing the costs of the investments on innovations and for avoiding the frustration of the innovative people.

Thabane et al. (2010, p. 3) also indicated that a pilot study is "a small single-centre study" and "a small study that is similar in size to someone else's published study". Newfoundland Labrador (n. d., p. 11) also indicated that a pilot is "an initial prototype of a system into production, targeting a limited scope of the intended final solution" and that "the purpose of a pilot project is to test, often in a production environment, whether the system is working as it was designed while limiting business exposure" (p. 11). The definition of Proof of Concept Study can be summarized as a very small study which purpose is the validation of the functionality of the application of the innovative idea. Also, the definition of Pilot Study can be summarized as a small study which is developed after the proof of concept study, and which purpose is to elaborate and prove an initial prototype of the final solution in a real small case.

One of the main models for determining the maturity level of innovation management of the organizations is the I2MM, which was proposed by Mûller-Prothmann and Stein (2011) for Lean Assessment of Innovation Capability with five levels and the following characteristics:

1. Level 1: Chaotic. Chaotic organization, disorganized, unregulated, without integration with stakeholders, conservative, firefighter behavior, and nonintegrated communication.

2. Level 2: Organized. Documented processes and sub-processes, although not harmonized, some claims management processes and customer feedback, innovative ideas rejected as unfeasible, identification of stakeholders, and the transfer of knowledge or cooperation with other areas is considered as unimportant.

3. Level 3: Standardized. Documented and harmonized processes, minimized risks, learning culture is constant, cooperation with stakeholders has been 
improved but remains an exception, the ideas are evaluated and rewarded with incentives, quality management is implemented and harmonized, and benchmarking of markets is developed.

4. Level 4: Predictable. Planed and evaluated processes through indicators and expected results, the tools and techniques are accessible to each employee, continuous participation of stakeholders, and the knowledge management stimulates the process improvement.

5. Level 5: Black Belt. Processes are improved continuously, organization realizes strategic foresight with knowledge networks inside and outside the organization, innovation methods are suggested by stakeholders, and financial incentives to creativity.

The characteristics of the maturity levels of the I2MM oriented to the organizations to the continuous improvement in the innovation management. In these decades, the use of maturity models is widespread in diverse management topics.

Deutsch (2013) explained the steps of the Seeking Solutions Approach, which were the following: (a) the call for problems (the problem-sourcing phase), (b) problem selection (validation of the problems by ambassadors), (c) problem broadcast (it is developed through a dedicated web tool, being targeted and broad), and (d) Seeking Solutions Event (a real collaborative event) (p. 8). Belkhir (2015) also proposed a 3 -stage roadmap of an organization towards becoming a sustainable organization, which reflects the level of maturity of the organization; these were the following:

1. Stage 1: Sustainability Strategy: Organization Alignment \& Capability Building

a.Policy:

- Company-wide sustainability training

- Set reductions targets in GHE, energy, resource consumption, and emissions, along with supporting incentive system

b. Entrepreneurship:

- Encourage and reward initiative and risk-taking in the development of novel solutions

- Provide a protected risk capital proof of concept and validation those novel solutions

c. Design:

- Employ sustainable design principles, e.g., modularity, bio-mimicry, recyclability, into the product design process

- Develop quantitative measurement models for sustainability impact, e. g. GHE, toxicity, energy consumptions, water consumption, material reusability 
2. Stage 2: Goal Setting: New Products \& Services

a. Policy:

- Set strict sustainability compliance targets for suppliers - Set goals and targets for switching to renewable energy

b. Entrepreneurship:

- Institutionalize entrepreneurial culture by promoting the successful ones

- Gradually shift resources towards emerging business and scale up

- Create new brands and/or businesses that are not tainted by legacy products

c. Design:

- Design new products against strict sustainability criteria

- Design manufacturing processes that meet those same guidelines

- Develop and/or acquire software tools for integrated management of sustainability on a life cycle basis

3. Stage 3: Institutionalization; Disruptive Innovation; New Business Models

a. Policy:

- Mandate $100 \%$ renewable energy target internally and $50 \%+$ for suppliers - Become a B-corp

- Hire and fire according to sustainability criteria

- Lead the development of industry standards and share best practice

b. Entrepreneurship:

- Replicate the 3 levers at the business unit level

- Invest in and acquire innovative startups with complementary products and a dedicated sustainability strategy

- Leverage your entrepreneurial core competency to disrupt your competitors

c. Design:

- Design products that combine form, function and aesthetic, but cause zero harm in any stage of their lifecycle, and are $>80 \%$ reusable.

- Design a supply chain that uses $80 \%+$ renewable energy and state of the art of water preservation

- Design new business models that achieve higher efficiencies throughout your value chain

Brown (2008) defined "design thinking" as follows: "a discipline that uses the designer's sensibility and methods to match people's needs with what is technologically feasible and what a viable business strategy can convert into customer value and market opportunity" (p. 96). Mootee (2013) also indicated that "design thinking" is the search for a magical balance between business and art, structure and chaos, intuition and logic, the concept and execution, the playful spirit and the formality, and the control and the freedom (p. 32). Additionally, Rim (2012) indicated the design-thinker characteristics: (a) Human and environment centered 
concern, (b) ability to visualize, (c) predisposition toward multifunctionality, (d) systemic vision, (e) ability to use language as a tool, (f) affinity for teamwork, and (g) avoiding the necessity of choice. Brown (2008) also described the characteristics to look for in design thinkers: (a) empathy, (b) integrative thinking, (c) optimism, (d) experimentalism, and (e) collaboration. Furthermore, Brown (2008, p. 88) explained how design thinking happens:

\section{A. Inspiration: Expect Success}

a. Build implementation resources into your plan.

b. What's the business problem? Where's the opportunity? What has changed that soon may change? c.Look at the world: observe what people do, how they think, what they need and want

d. What are the business constraints (time, lack of resources, impoverished customer base, shrinking market)?

e. Pay close attention to "extreme" users, such as children or the elderly. $\mathrm{f}$. Have a project room where you can share insights, tell stories.

g. How can new technology help?

h. Are valuable ideas, assets, and expertise hiding inside the business? i. Organize information and synthesize possibilities (tell more stories)

\section{B. Ideation: Brainstorm}

a. If it is necessary, back to steps " $h$ " and " $i$ " of the inspiration. $b$. Make many sketchers, concoct scenarios.

c. Build creative frameworks (order out of chaos). d. Apply integrative thinking.

e. Put customers in the midst of everything; describe their journeys. $f$.

Prototype, test, prototype, test, ...

g. Tell more stories (they keep ideas alive).

h. Communicate internally - don't work in the dark!

i. Prototype some more, test with users, test internally.

\section{Implementation: Execute the Vision}

a. Help marketing design a communication strategy.

b. Make the case to business - spread the world.

c. Move on to the next project - repeat. d. Go to "A. Inspiration" Phase.

In the previous decades, Design Thinking was one of the most popular innovation models of the organizations in the world. Lugmayr, Stockleben, Zou, Anzenhofer, and Jalonen (2014) also indicated that Stanford created the following design thinking phases: (a) empathize, (b) define, (c) ideate, (d) prototype and (e) test, and also, showed and improved the version created by Plattner, which included the selflearning at the beginning and the business plan at the end, converting the seven design thinking's phases as follows: (a) self-learning, (b) empathize (which included observe and understand), (c) define (includes the setting of a point of view), (d) ideate, 
(e) prototype, (f) test, and (g) business plan. Dunne and Martin (2006) also proposed the cycle of design thinking as follows: (a) generate ideas (abduction), (b) predict consequences (deduction), (c) test, and (d) generalize (induction). Additionally, Rim (2012) proposed her adapted "design thinking competency model", which includes the following competencies:

\section{A. Demonstrate Design Thinking (DT) Skills}

a. Locate/Use Resources

i. Identify needs and set goals ii.Find Resources:

- Seek up-to-date resources

- Employ up-to-date resources

iii. Analyze and Synthesize Resources

- Combine info from different resources

- Generate ideas from information

iv. Discern Resources

- Assess resource credibility - Assess resource quality

v. Create Argument

- Pose argument based on evidence

b. Iterate Diagrams

i. Tinker

- Experiment with a system

- Break down a system

- Model/prototype a system

- Build theory

ii. Create

- Create models iii. Test

- Test model

- Generate feedback

- Modify model/redesign

- Reevaluate model

- Make decision (accept/reject model)

c. Innovate Design

i. Design context

- Recognize opportunities for innovation based on research ii.

Design process

- Innovate roach(es) to iteration

iii. Design esthetics

- Represent innovation in an aesthetically coherent way

\section{B. Use DT terminology}

a. Understand DT terms

i. Identify DT terms (e.g., sketches, prototype, iteration, action plan, and so on)

ii. Apply DT terms in the right context 


\section{Employ DT Behavior}
a. Show persistence
b. Manage time
c. Adapt parameters on demand

Brown (2008, p. 90) explained how to make design thinking part of the innovation drill: (a) begin at the beginning, (b) take a human-centered approach, (c) try early and often, (d) seek outside help, (e) blend big and small projects, (f) budget to the pace of innovation, (g) find talent any way you can, and (h) design for the cycle. Dougherty and Hardy (1996) also indicated that:

The literature suggests that for a mature organization to develop the capacity for sustained innovation, it must successfully make these innovation-to-organization connections in three key areas: (1) make resources available for new products, (2) provide collaborative structures and processes to solve problems creatively and connect innovations with existing businesses, and (3) incorporate innovation as a meaningful component of the organization's strategy. (p. 1122)

Euchner and Ganguly (2014) explained the Goodyear's business model innovation process, which has the following processes: (a) demonstrate value creation, (b) generate business model options (coherence, competitiveness, path to profits), (c) identify risks for each option (execution, co-innovation, adoption), (d) prioritize risks, (e) reduce risk through business experiments, and (f) organize for incubation (p. 34). Merfeld (2014) also proposed the FastWorks framework, which includes the following processes: (a) understand the customer's need, (b) identify leap-offaith assumptions, (c) define your minimum viable products (MVPs), (d) establish learning metrics, and (e) pivot or persevere (p. 30). Additionally, Kaski, Alamäki and Moisio (2014) explained the InnoCamp model, as a rapid innovation method, tested at Vierumäki Sport Institute for two days with sport companies, which were looking for new ideas or solutions for their existing sport services and products. The processes of InnoCampo, for pre-assignments, the first and the second day, were the following:

\section{A. Pre-Assignments}

- Pre-understanding

B. First Day

- Company task sharing

- Idea Creation: Several methods • Evaluations

C. Second Day

- Selection

- Improvement, concept creation - Selling, pitch 
Frederic, Lam, and Martin (2014, p. 103) introduced a Lean Innovation Model, with the following processes: (a) Start; (b) Conduct initial assessment; (c) Identify gaps and ITAG actions. ITAG means Innovation Transformation Action Grid (ITAG) and is composed by Culture, Process, and Infrastructure; (d) Implement ITAG actions; (e) Conduct assessment; and (f) Back to step C; and Nientied (2015) explained that the concept of "Lean Startup" was introduced by the entrepreneur Eric Ries in 2011 in his book "The lean startup, How today's entrepreneurs use continuous innovation to create radically successful business". Nientied (2015) also indicated that Lean Startup is "a system for developing a business or product in the most efficient way possible to reduce the risk of failure" (p. 20), and relies on "structured experimentation, iterative product releases, and customers' feedback to generate validated learning" (p. 20). Additionally, Nientied (2015, p. 21) explained that Ries used five principles for the lean startup's approach:

1. Entrepreneurs are everywhere - not just in a garage, but in any size company. 2. Entrepreneurship is management - a startup is an institution, not just a product.

3. Validated learning - a startup learns how to build a sustainable business; it is not there to just make stuff or money.

4. Build-measure-learn - a startup is to turn ideas into products, measure how customers respond and then learn whether to pivot or persevere (i.e., a feedback loop).

5. Innovation accounting - a new way of accounting is needed to measure progress, set up milestones, and prioritize work.

Nientied (2015) also indicated the Ries' feedback loop "Build-Measure-Learn", as follows: (a) ideas, (b) build, (c) product, (d) measure, (e) data, and (f) learn. As was presented, the diverse methods and models have been centered in the creative processes and construction of the products; however, did not integrate the diverse management topics related to the innovation management.

\section{Standards Related to the Innovation Management}

The most known standards related to the innovation management are the following:

1. The UNE 166002:2014 R\&D\&I Management: R\&D\&I management system requirements. This standard has the following components:

\section{A. Context of the organization}

a. Knowledge of the organization and its context

b. Comprehension of the needs and expectations of the stakeholders c. Management system of the R\&D\&I 


\section{B. Leadership}

a. ision and strategy of the R\&D\&I b. Policy of the R\&D\&I

c. Leadership and commitment of the management d.Promotion of an innovation culture

e. Roles, responsibilities, and organizational authorities

C. Planning

a. Risks and opportunities

b. Purposes of the R\&D\&I and plan for obtaining them

D. Support of the $R \& D \& I$

a. Organization of the roles and sponsibilities b. Resources

c. ompetencies d. Awareness

e. Communication

f. Documented information

g. Intellectual and industrial property, and knowledge management $\mathrm{h}$. Collaboration

i. Technological surveillance and competitive intelligence

E. Operating Processes of $R \& D \& I$

a. Generalities

b. Management of Ideas

c. Development of R\&D\&I projects

d. protection and exploitation of the results e. Introduction to the market

f. Results of the operating processes of the R\&D\&I

\section{F. Performance Evaluation of the Management System of R\&D\&I}

a. Monitoring, measuring, analysis and evaluation

b. Internal Audit

c. Evaluation by the Management

\section{G. Improvement of the Management System of $R \& D \& I$}

A guide for implementing the UNE 166002:2006 to firms in the residential building, was found in Gil, Varela, and González (2008). This is the closest approximation to this methodological proposal; however, the scope of MIM3 is broader than the previous one, due to the details which will be observed in the the "Methodological Proposal" section.

2. ONR CEN/TS 16555-1 Innovation Management - Part 1: Innovation Management System (prCEN/TS 16555-1:2012). This standard refers the following parts of the management innovation:

Part 1: Innovation Management System, 
Part 2: Strategic Intelligence Management,

Part 3: Innovation Thinking,

Part4: intellectual Property Management,

Part 5: Collaboration Management,

Part 6: Creativity Management,

Part 7: Innovation Management Assessment

(Austrian Standards Institute, 2013).

3. ISO/TC 279 Innovation management. The scope of this standard is the standardization of the terminology tools, methods, and interactions among the relevant parties to enable innovation in the organizations (ISO, 2013).

4. BS 7000-1:2008 Design Management Systems - Part 1: Guide to Managing Innovation. The scope of the BS 7000-1:2008 (British Standards, 2008, p. 15) includes the following phases and stages:

\section{A. Phase 1: Explore the Potential / Set the Context}

a. Stage 1: Review the current innovation practices to determine the potential for improvement $b$. Stage 2: Create future vision

c. Stage 3: Draw up mission statement related to innovation

d. Stage 4: Distil innovation objectives and strategies from the organization's objectives and strategies

\section{B. Phase 2: Establish foundation}
a. Stage 5: Determine the innovation highway
b. Stage 6: Plan introduction of organization's new approach to innovation
c. Stage 7: Communicate essence of innovation mission, objectives and strategies
d. Stage 8: Promote innovation nurturing culture
e. Stage 9: Reinforce infrastructure and expertise to manage innovation

C. Phase 3: Implement changes
a. Stage 10: Draw up master innovation programme
b. Stage 11: Implement programme and support new approach to innovation
c. Stage 12: Evaluate progress and contribution of master innovation programme

D. Phase 4: Build on expertise and enhanced reputation
a. Stage 13: Build distinctive competencies and competitive advantage through innovation
b. Stage 14: Document, share, publicize and celebrate achievements through innovation


c. Stage 15: Enhance organization's reputation through innovation

d. Stage 16: Review and refine overall approach to innovation.

\section{Project Management Methodologies}

The most important project management methodologies which were found in the literature are the following: Project Management Body of Knowledge (PMBOK) and Critical Chain. The Project Management Institute (2013) proposed for the project management in its $\mathrm{PMBOK}$, the following groups of processes:
(a) initiation,
(b) planning,
(c) execution,
(d) monitoring and control,
(e) closing processes.

The Project Management Institute (2013) also proposed in its PMBOK, the following knowledge areas of the project management:

1. Integration Project Management. It includes the following processes: a) to develop the project charter, b) to develop the management plan of the project, c) to direct the execution of the project, d) to monitor the work of the project, e) to develop an integrated control, and e) to close the phase or project.

2. Project Scope Management. It includes the following processes: a) scope management plan, b) gather requirements, c) to define the scope, d) to create the work breakdown structure, e) to validate the scope, and f) to control the scope.

3. Project Time Management. It includes the following processes: a) Schedule management plan, b) to define the activities, c) to sequence the activities, d) to estimate resources of activities, e) to estimate the duration of activities, f) to develop the schedule, and g) to control the schedule.

4. Project Cost Management. It includes the following processes: a) to plan the management of costs, b) to estimate the costs, c) to prepare the cost budget, and d) to control costs.

5. Project Quality Management. It includes the following processes: a) to plan the quality management, b) to realize the quality assurance, and c) to control the quality.

6. Project Human Resources Management. It includes the following processes: a) to plan the management of human resources, b) to contract the project team, c) to develop the project team, and d) to direct the project team. 
7. Project Communications Management. It includes the following processes: a) to plan the management of the communications, b) to manage the project communications, and c) to control the communications.

8. Project Risk Management. It includes the following processes: a) to plan risk management, b) to identify risks, c) to analyze risks qualitatively, d) to analyze risks quantitatively, e) to plan risk response, and f) to control risks.

9. Project Procurement Management. It includes the following processes: a) to plan the procurement management plan, b) to execute the acquisitions, c) to control the acquisitions, and d) to close the acquisitions.

10. Project Stakeholder Management. It includes the following processes: a) to identify stakeholders, b) to plan the management of stakeholders, c) to manage the stakeholder participation, and d) to monitor the participation of stakeholders.

For the time management of the projects, Goldratt (1997) proposed the critical chain methodology, which is based on the methodology of five steps for the continuous improvement of the Theory of Constraints, and has the following steps:

\section{A. Step 1: To identify the constraints of the system.}

This step consists of the identification of the critical chain, which is different to the critical path. The critical chain is the largest sequences of tasks, considering not only the time, whether considering the time and the resources for developing the tasks.

B. Step 2: To decide how to exploit the constraints of the system.

This step consists of the decision of cutting the slack time of the time estimation of tasks and put the slack time as a project buffer at the end of the project for protecting the whole project and not each one of the tasks.

C. Step 3: To subordinate all the tasks to the previous decision.

This step consists of the introduction of slack time to the tasks before the task which are parts of the critical chain. Also, this step consists of the introduction of a buffer of resources, which is implemented through the continuous previous communication to the resources whom will support to a project, with the purpose that be available for attending the tasks of the project when the personnel or the tasks of the project needs the support.

D. Step 4: To increment the capacity of the system.

This step consists of hiring more personnel or acquiring more equipment for improving the velocity of the system. 
E. Step 5: To back to the step one and doesn't permit that the inertia causes a constraint.

This step consists of the periodic evaluation of the critical chain for being sure that the time protection is put in the right way.

The critical chain methodology must be implemented to each one of the projects and for the whole project management system. Goldratt (1997) proposed the criteria of a resource, for prioritizing the attention to a task: (a) end date of the project, (b) type of task which requires the attention, (c) consumption of the project buffer, and (d) consumption of the feed buffer (slack time before the tasks which are parts of the critical chain). Goldratt (1999) also proposed the management indicators for project management: (a) advance percentage of the critical chain of the project, (b) proportion of the consumption of the project buffer and the finished portion of the critical chain, and (c) consumption velocity of the project buffer.

\section{Yellow Pages of Knowledge Management}

Bagnoli and Vedovato (2014) explained about the use of information and communication technologies for knowledge management, indicating that "a large variety of tools, instruments and approaches, ranging from internal bulletin boards, to corporate Yellow Pages of who knows what" (p. 536) are leading the solutions for archiving and storing the knowledge. Grant (2013) also explained that "most of the companies we studied have instituted some form of 'expert locator' or 'corporate yellow pages' that enables individuals with particular experiential knowledge to be identified and contacted" (p. 98). Additionally, Pinho, Rego and Cunha (2012) indicated that yellow pages are registers about "who knows what" (p. 220).

\section{Financial Criteria for Evaluating the Innovation Management}

The financial criteria for evaluating the innovation management must include the following theoretical framework: free cash flow, direct costing, total cost of ownership, and MEVGIT. Chih-Chang (2013) indicated that free cash flow is "the balance of cash inflows and outflows" (p. 1). Chih-Chang (2013) also explained that free cash flow indicates "the ability of corporations to expand, and is commonly known by stock market analysts as capital expenditures" (p. 1). Additionally, Kousenidis (2006, p. 649) explained that the majority of finance text books defined free cash flow as follows: "the after tax operating earnings of a company plus noncash charges less investment in working capital, property, plant and equipment, and other assets (Copeland et al., 1991)"; Kousenidis (2006) also indicated that free cash flow "requires that cash flow does not incorporate any financing-related cash flows, such as interest expense or dividends" (p. 649). 
About the direct costing, Klychova, Zakirova, Zakirov, and Valieva (2015) indicated that "is intended to include in the cost of production and ending stocks estimate only variable production costs and allocation on financial result of the total amount of fixed costs without distribution by product types" (p. 308). Klychova et al. (2015) also explained that: "the purpose of this method is increasing the speed of decisionmaking on pricing and possibility of analyzing the relationship of the costs, volume of production (sales) of products and profit (CVP-analysis) as well as analysis of break-even point" (p. 308). Additionally, Iotti and Bonazzi (2014) explained that "the direct costing assigns only the costs directly attributable to the individual productions, while overhead costs are not allocated and are briefly summarized at the close of the reclassified income statement" (p. 1492).

Bibo (2014) explained that the Total Cost of Ownership (TCO) is "a technique which can be used to make sure that all associated costs over a given time period are considered" (p. 89). Laudon and Laudon (2012, p. 196) also indicated that the total cost of ownership of technology assets must include:

A. Hardware acquisition: Purchase price of computer hardware equipment, including computers, terminals, storage, and printers.

B. Software acquisition: Purchase or license of software for each user. C. Installation: Cost to install computers and software.

D. Training: Cost to provide training for information systems specialists and end users and Support: Cost to provide ongoing technical support, help desks, and so forth.

E. Maintenance: Cost to upgrade the hardware and software.

F. Infrastructure: Cost to acquire, maintain, and support related infrastructure, such as networks and specialized equipment (including storage backup units).

G. Downtime: Cost of lost productivity if hardware or software failures cause the system to be unavailable for processing and user tasks.

H. Space and energy: Real estate and utility costs for housing and providing power for the technology.

TCO can be used not only for information technology projects. Diverse types of projects can use the indicated criteria if the information technology assets are replaced by other types or assets. Finally, Alfaro (2017) proposed the Methodology for Evaluating the Value Generation of Information Technologies (MEVGIT), which consists of the following steps:

A. To calculate the additional inflow, which will be collected by the product or result of the project.

a. To calculate the additional contribution margin (in the case of firms) or the additional gross domestic product (in the case of nonprofit governmental entities) due to the product or result of the project 
For firms:

i. To calculate the additional contribution margin due to the increase of sales to the current clients.

ii. To calculate the additional contribution margin due to the increase of sales to new clients.

iii. To calculate the additional contribution margin due to the organization would avoid the loss of sales.

iv. To calculate the additional contribution margin due to the reduction of the variable cost of sales.

For nonprofit governmental organizations:

i. To analyze how to convert the nonfinancial benefits with the goods or services of the nonprofit governmental entities, to amounts of gross domestic product.

ii. To calculate the amount of gross domestic product which will be increased through the product or result of the project.

b. To calculate the savings due to the product or result of the project

i. To calculate the savings due to the reduction of investments. ii.

To calculate the savings due to the reduction of expenses.

B. To calculate the additional outflows, which will be collected by the product or result of the project.

a. To calculate the additional investments: hardware acquisition, software acquisition, installation, infrastructure, furniture and equipment, and others

b. To calculate the additional expenses: personnel, advertising, training, support, maintenance, inactivated time, space and energy, and others

C. To calculate the net flow. The calculation of the net flow is the difference of the additional inflows and the additional outflows.

D. To estimate the discount rate. The discount rate must consider the following criteria: (a) to be higher than the risk-free rate, (b) to be higher than the average return on investment of the firms of the economic sector of the country or region, (c) to be higher than weighted average cost of capital, and (d) to be equal or greater than a minimum discount rate that the board of directors determined.

E. To calculate the net present value. For calculating the net present value, the discount rate and the net flow must be considered. Each one of the net flow at the end of each period must be discounted dividing $(1+$ discount rate $) i$, where " $i$ " is each one of the periods. The sum of the discounted net flows of each period will be the net present value. 


\section{The Proposed Methodology: MIM3}

The proposed MIM3 methodology integrates the generation of ideas of innovative projects in an aligned manner with the strategic planning of the organizations through the concordance with the organizational purposes and goals of the organizations and the areas or processes of the organizations joined to the manner in which the innovative project idea will contribute to the goals searching the quantification of the impact. MIM3 also includes the knowledge areas (integration management, scope management, time management, cost management, quality management, human resources management, communications management, risk management, acquisitions management and stakeholders management) of the project management according to Project Management Body of Knowledge (Project Management Institute, 2013) in a summarized manner and the use of the Critical Chain (Goldratt, 1997), with the processes of some of the main innovation models and innovation methods which were found in the literature review, considering the good practices of the standards of innovation management.

MIM3 also includes some knowledge management good practices, such as the yellow pages and the evaluation of the value generation of the innovative projects with a procedure based on the MEVGIT methodology (Alfaro, 2017), which is also based on free cash flow, total cost of ownership and the direct costing. The proposed methodology (MIM3) needs to be applied to some organizations for validating it rigorously in the practice; however, a first version for the evaluation is finished and is composed by policies, processes and procedures, according to the following explanations:

\section{Policies}

The general policies which are necessary for the application of the methodological proposal are the following:

1. This methodological proposal is applicable to all the innovative projects which the personnel want to present in each one of the processes or areas of the organization.

2. The innovation area will maintain a service vocation for all the personnel of the processes or areas, all the time. In this way, the innovation area will support with the corresponding technical knowledge to the diverse proposals of innovation projects.

3. The innovation area will consider "Idea of an Innovative Project" to an idea of project which would generate value and would have a creative or new component for the reality of the process of the organization. 
4. The innovation area must receive and evaluate all the ideas of innovative projects which each worker of the organization or its stakeholders consider innovative project.

\section{Processes and Procedures}

The processes of the MIM3 methodological proposal are depicted in Figure 1. The processes and procedures of MIM3 are detailed as follows:

\section{Generate and evaluate the „Idea of Innovative Project“.}

A. Develop or update the policy framework for the innovation management in the organization (AENOR, 2014). In this policy framework, the percentages of property rights for the innovative projects and the whole norms for the innovation processes must be established; also, it must be aligned to the strategic plan of the organization.

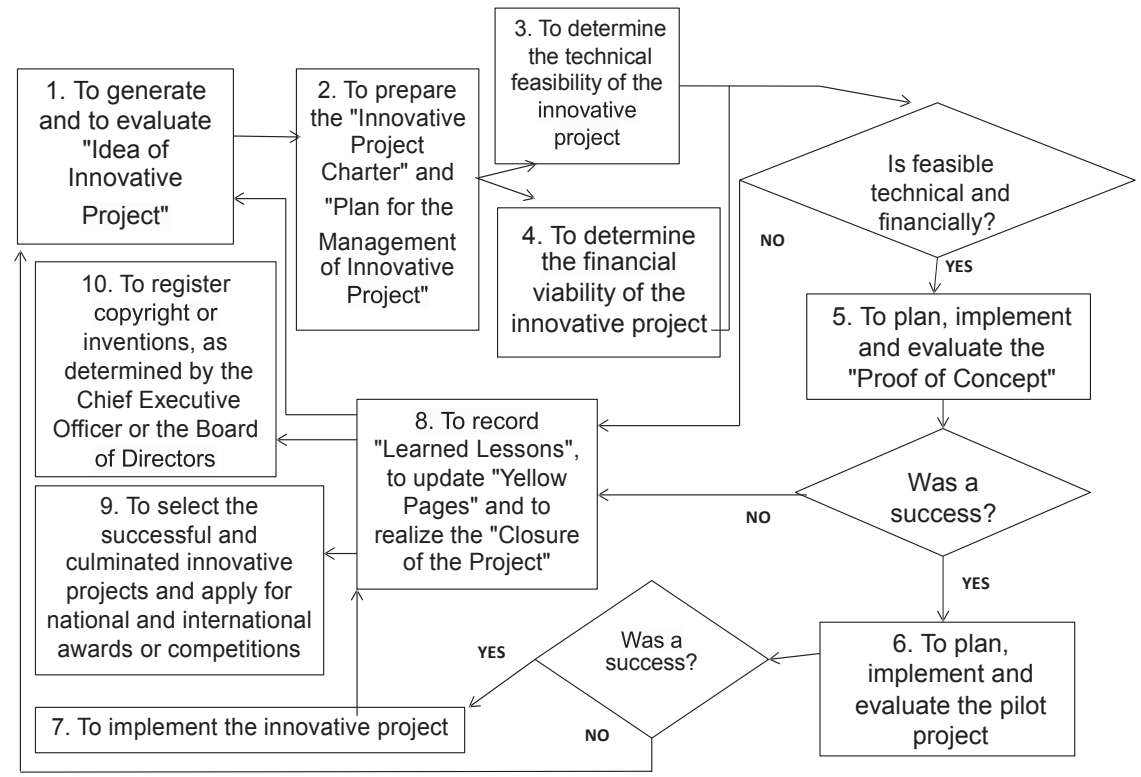

Figure 1. MIM3: Methodology of Innovation Management for obtaining the level 3 of the I2MM in the organizations. 
B. Hire training about the state of art knowledge related to the economic sector and the markets of the organization, according to the strategic plan of the organization. This training must be part of a continuous and sustainable training of the organization (Belkhir, 2015). Also, this training must stimulate the development of the characteristics of design thinkers into the personnel of the organization (Rim, 2012; Brown, 2008). According to Rim (2012), the designthinker characteristics are the following: (a) Human and environment centered concern, (b) ability to visualize, (c) predisposition toward multifunctionality, (d) systemic vision, (e) ability to use language as a tool, (f) affinity for teamwork, and (g) avoiding the necessity of choice. Rim (2012) also indicated his adaption to the design thinking's competency model: (a) Demonstrate Design Thinking (DT) Skills, (b) Use DT terminology, and (c) Employ DT Behavior. According to Brown (2008), the characteristics to look for in design thinkers, are the following: (a) empathy, (b) integrative thinking, (c) optimism, (d) experimentalism, and (e) collaboration.

C. Conduct workshops to analyze the problems of the stakeholders related to our processes. A list of categories of problems of the organization and its processes in relation with is stakeholders must be identified, for a better comprehension of their needs and expectations (AENOR, 2014; Deutsch, 2013). At the end of the workshops, sessions for proposing solutions to the analyzed problems must be obtained.

D. Get a list of ideas of innovative projects as a result of the workshops or as a result of calls for internal or external competitions (Deutsch, 2013).

E. For each innovative project which was presented:

a. Assess whether the idea will contribute to achieving organizational goals and objectives: How would contribute to achieving the goal? and How much would be the contribution to achieving the goal? (If it is possible to be calculated) (AENOR, 2014; Project Management Institute, 2013).

b. Invite the innovative team to justify the innovative project idea.

c. If it is possible to quantify the contribution to achieving the goals: Then

i. Formulate, propose, evaluate, and approve or reject the project together in the Evaluation Committee of Innovations.

To prepare the form „FR-MIM3-001-001 Idea of Innovative Project“, please see Table 2 in the Appendix.

Evaluate and / or adjust the "Idea of Innovative Project" exposed in the above form together with the staff of the processes that would be involved. If the project is accepted by majority: Then

Seek approval from the managers of the processes involved. 
If the managers of the involved processes approve the project and it is possible to develop the project with the budget of their functional areas,

Then:

Continue with Step 2: Prepare the „To elaborate the Innovative Project Charter“ and „The Plan of the Management of Innovative Project”.

Else

Seek the approval from the Chief Executive Officer, following the relevant administrative channels.

If the Chief Executive Officer approves the idea of innovative project, Then

Continue with Step 2: ,To prepare the „Innovative Project Charter“ and the „Plan

Else of the Management of Innovative Project”.

Search technical advice, rethink, or discard the innovative idea. Else

If the team that presented the Idea of Innovative Project persists, Then:

Seek the approval from the managers of the involved processes.

If the managers of the involved processes approve the project and it could be developed with the budget of their functional areas, Then:

Continue with Step 2: ,To prepare the "Innovative Project Charter" and „Plan of the Management of Innovative Project"“.

Else

Seek the approval of the Chief Executive Officer, following the relevant administrative channels.

Else

Search technical advice, rethink or discard the innovative idea.

Else

ii. Search technical advice, rethink, or discard the innovative idea.

2. Prepare the „Innovative Project Charter“ and „Plan for the Management of Innovative Project".

A. Prepare the „Innovative Project Charter“ using the form „FR-MIM3-002-001 
Innovative Project Charter". The Innovative Project Charter must include the following items: name of the project, high level budget, purpose of the project, justification of the project, scope of the project, phases and results of each phase, and the project team (Project Management Institute, 2013). See Table 3 in the Appendix.

B. Develop the „Plan for the Management of Innovative Project“ using the „FR-MIM3-003-001 Template for the Innovative Project Management Plan“. See Table 4 in the Appendix. This plan for the management of the innovative project must contain all the phases as was determined in the project management methodology of the organization, including the following:

a. Determine the technical feasibility of the innovative project. For this step, you can use the form „FR-MIM3-004-001 Technical Evaluation of the Project" and the form "FR-MIM3-005-001 Risks Management of the Innovative Project”. See Table 5 and Table 6 in the Appendix, respectively.

b. Determine the financial viability of the innovative project. For this step, you can use the form ,FR-MIM3-006-001 Financial Evaluation of the Project". See Table 7 in the Appendix.

c. Plan, implement and evaluate the Proof of Concept (Thabane et al., 2010; Newfoundland Labrador, n. d.).

d. Plan, implement and evaluate the Pilot Project (Thabane et al., 2010; Newfoundland Labrador, n. d.).

e. Implement the Innovative Project.

f. Register Learned Lessons (to use the form „FR-MIM3-007-001 Registration of Innovative Project's Learned Lessons“, which is in the Table 8 in the appendix one) and Form of Project Closure (use the form „FR-MIM3-008-001 Form of Project Closure“, which is provided in Table 9 in the Appendix).

Further, the Plan for the Management of the Innovate Project must be aligned to the project management methodology of the organization, in compliance with the best practices of project management, including the following processes (Project Management Institute, 2013):
(a) integration management,
(b) scope management,
(c) time management, 
(d) cost management,

(e) quality management,

(f) human resources management,

(g) communication management,

(h) risk management,

(i) procurement management,

(j) stakeholders management.

3. Determine the technical feasibility of the innovative project.

A. Investigate diverse alternatives for implementing the innovative project, in the national and global market, in academic and business sources with recognized prestige, such as:

a. Studies of market research companies: Gartner, Forrester, IDC or other firm to which the organization has the access.

b. Literature review articles or investigations of prestigious academic sources, such as: EBSCO, Proquest, JSTOR, Hinari, Google Scholar, Social Science Research Network (SSRN Database), Cybertesis, Dialnet, virtual libraries of central reserve banks, virtual libraries of universities, among others, depending of the characteristics of the type of innovation.

c. Public information of the providers of the diverse types of innovations: theories, methodologies, technologies, etc.

In the case that due to the nature of the innovative project, the staff of the innovation area does not have the competences or sufficient experiences to develop this activity, the innovation area should hire individuals or firms, which can develop consultancy works on these issues for the organization.

B. Develop preliminary technical specifications and / or preliminary terms of reference, which detail the requirements for developing the innovative project.

C. Request the submission of technical and financial proposals to suppliers, taking in account the technical specifications and / or terms of reference (on the basis of the preliminary technical specifications and / or preliminary terms of reference). This information must be provided to a minimum of three suppliers (ideally should be sent to all suppliers to which the organization has access). 
D. Evaluate the technical proposals (technical specifications and / or improved terms of reference) which were sent by each supplier and next, to complement and / or correct the technical specifications and / or terms of reference with the information taking into account the relevant information for each supplier.

E. Validate the specifications and / or terms of reference made in the previous point, with the staff of the processes with whom the project would be developed or applied.

F. Elaborate calculations to estimate the improvements (time, increase of goals, efficiency, effectiveness, etc.) under three scenarios: pessimistic, average and optimistic.

G. Use the form "FR-MIM3-004-001 Technical Evaluation of the Project" for evaluating the diverse criteria and determining the scores of the technical possible solutions.

H. If the results of scores of the previous point are positive: Then

Declare that the innovative project is technically feasible.

Continue with the step 4: To determine the financial viability of the innovative project.

Else

Seek additional technical assistance, rethink or refute the innovative project.

\section{Determine the financial viability of the innovative project.}

A. Evaluate the financial proposals which have been received from suppliers and that were requested in point $3 \mathrm{C}$.

B. Calculate the net present value of the innovative project with the direct costing and the total cost of ownership approaches, taking into account the following aspects: additional inflows (additional contribution margins and savings), additional outflows (additional investments and additional expenses), the evaluation period and the discount rate (minimum attractive return rate), which was determined by the Finance Area of the organization. It must consider three scenarios: pessimistic, average, and optimistic. For detailing the costs, to elaborate the form "FR-MIM3-009-001 Budget of Outflows of the Innovative Project", please refer to Table 10 in the Appendix. For calculating the net present value, use the form "FR-MIM3-006-001 Financial Evaluation of the Innovative Project" (Chih-Chang, 2013; Klychova et al., 2015; Bibo, 2014; Laudon \& Laudon, 2012; Euchner \& Ganguly, 2014). 
C. If the net present value of the optimistic and average scenarios is positive: Then

Declare the financial viability of the innovative project.

Continue with step 5 ,plan, implement and evaluate the „Proof of Concept“".

Else

Declare that the project is not financially viable, unless the innovative project is not a generator of income or if the investment for the project is very high.

5. Plan, implement, and evaluate the ",Proof of Concept“.

A. Prepare the schedule of the „Proof of Concept" with the form "FRMIM3-010-001 Schedule of the Innovative Project", please refer to Table 11 in the Appendix.

B. Run the „Proof of Concept““.

a. Empathize with the customer or end user and get information about your problem (Lugmayr et al., 2014; Merfeld, 2014).

b. Define the problem to be solved for the customer or end user, more clearly (Lugmayr et al., 2014).

c. Devise the resulting product of the project, more accurately.

d. Develop a prototype of the product resulting from the project. If the project team considers adequate for giving an order to the elaboration of the prototypes, use the form "FR-MIM3-011-001 Control of Changes of the Innovative Project", per each change in the prototype. To this aim, see Table 12 in the Appendix.

e. Design the business model for the prototype or the product resulting from the innovative project, at this stage.

f. Assess whether the prototype and the associated business model meet the needs of the customer or end user (Euchner \& Ganguly, 2014; Frederic, Lam, and Martin, 2014).

g. If the results were negative and there is still budget:

Then

Return to step „a“.

Else

Go to step ,5.C“. 
C. Evaluate the development and results of the „Proof of Concept“.

D. If the results of the „Proof of Concept" are positive:

Then

Communicate the results to the stakeholders, considering the previous elaborated form "FR-MIM3-012-001 Communications Management of the Innovative Project". See Table 13 in the Appendix. Continue with Step 6: "Plan, implement and evaluate the pilot project". Else

Seek additional technical assistance, rethink or refute the innovative project.

6. Plan, implement and evaluate the pilot project.

A. Prepare the implementation schedule of the pilot project. This schedule must be developed with the critical chain methodology (Goldratt, 1997; Goldratt, 1999).

B. Run the Pilot Project.

C. Evaluate the development and results of the pilot project.

D. If the results of the pilot project are sitive:

Then

Continue with Step 7: To implement the Innovative Project.

Else

Seek additional technical assistance, rethink or refute the innovative project.

7. Implement the Innovative Project.

A. Coordinate the budget.

B. Expand the organization or sequence of processes.

C. Develop a "Plan for the Management of the Pilot Project".

D. Implement technologies, theories and methodologies associated with the innovative project, according to the "Plan for the Management of the Pilot Project".

E. Evaluate the successful implementation of technologies, theories, and methodologies associated with the innovative project. 
F. Make the necessary adjustments after the evaluation.

8. Record „Learned Lessons “ to update ,, Yellow Pages “ and realize the „Closure of the Project".

A. Record „Learned Lessons“ of the innovative project (use the FRMIM3-007-001 Registration of Innovative Project's Learned Lessons).

a. Record the positive aspects that helped the proper management of the project in each one of its stages, as well as how to implement them.

b. Record the negative aspects that did not favor the project management in each one of its stages and how to minimize or eliminate their impact.

c. If a knowledge management information system exists, then introduces the information of the learned lessons into this system (Cohendet \& Simon, 2015).

B. Update the „Yellow Pages“ (Bagnoli \& Vedovato, 2014; Grant, 2013; Pinho, Rego, \& Cunha, 2012) of the innovative project (use the form „FR-MIM3-013-001 Yellow Pages of the Project"). See Table 14 in the Appendix.

a. To update the directory of internal experts (staff organization) on issues associated with the innovative project.

b. To update the directory of external experts (vendors which were people or firms) on the issues associated with the innovative project.

c. If a knowledge management information system exists, then introduces the information of the yellow pages into this system (Cohendet \& Simon, 2015).

C. Perform project closure.

a. Perform the administrative closure of the project. This closure should include the development of an article which would be sent to an indexed journal for publication, in addition to the formal closing of each of the stages, the closing of the financial accounts associated with the project, and the other documents required as part of the project management methodology of the organization.

b. Perform the closure of contracts that may be associated with the project. 
9. Select the successful and culminated innovative projects and apply for national and international awards or competitions.

A. Review the portfolio of successful and innovative projects that has been developed in the organization.

B. Select the innovative projects to be proposed in coordination with the areas or processes of the organization.

C. Propose the innovative projects that will postulate, to the Chief Executive Officer.

D. Apply for prizes or competitions of innovation, with the innovative projects that the Chief Executive Officer has approved. In the case that the prize is the „Award for Innovation in the organization“ should coordinate the awards with an advance of 6 months prior to such delivery.

10. Register copyright or inventions, as determined by the Chief Executive Officer or the Board of Directors (Austrian Standards Institute, 2013). This procedure includes the following tasks:

A. Record the projects whose results would have copyright registers (books, trademarks, distinctive signs, etc.).

B. Record projects whose results would be converted to registers of innovations (patents, utility models and industrial designs).

\section{Discussion and Conclusion}

Diverse innovation models, innovation methods, and innovation processes which were proposed previously for MIM3 didn't have a holistic focus and were based mainly on the creativity processes and the technical aspects related to the construction of the products, leaving aside the value generation, which must be the basic and the most important focus of the innovation management. The approach of the UNE 166002:2014 R\&D\&I Management: R\&D\&I management system requirements has the closest characteristics, when compared to MIM3. Then, MIM3 was built as a methodological proposal with a holistic focus, which includes the good practices of the following management areas: (a) strategic management, (b) project management, (c) innovation models and innovation methods, (d) standards for innovation management, (e) knowledge management, and (f) financial management. MIM3 could be difficult to implement in organizations without integrating managers with a strong leadership for meeting the competencies of the personnel associated with the diverse management areas, considering the diverse topics associated with 
innovation; furthermore, for the success of the implementation of MIM3 it could be necessary an extensive training about its related topics; however, due to its holistic focus and generic approach, MIM3 could be applied to diverse types of public or private organizations.

Future researches must test MIM3 with early adopter organizations, whose managers could be interested in initiating their innovation processes based on a structured methodology. The type of these organizations would be diverse, such as: high-technology organizations, universities, financial organizations, non-for-profit organizations, among others, depending of the level of maturity of the innovation management of the organization and the need for innovation of the organization in its sector or market. Also, it is necessary to study aspects of knowledge management information systems in the MIM3, such as the implementation of knowledge management information systems for the knowledge production (Business Intelligence - BI - and Customer Relationship Management - CRM- information systems) and knowledge integration (groupware information systems); also, the use of continuous information of market research firms, integrated with the use of the transaction processing information systems, the management information systems, the BI, and the CRM information systems.

\section{References}

AENOR. (2014). Gestión de la I+D+i: Requisitos del Sistema de Gestión de la $I+D+i$. Retrieved from http://www.aenor.es/aenor/normas/normas/fichanorma. asp?tipo $=$ N\&codigo $=$ N0052892\#.WUL1JGjyvIU

Ahmed, P. K., Shepherd, C. D., Ramos, L., \& Ramos, C. (2012). Administración de la Innovación. México, Mexico D. F.: Pearson Educación.

Alfaro, E. A. (2017). Urgent! ... To reward the innovation in information technologies with a real focus on value generation. In A. Brem, \& E. Viardot (Eds.), Revolution in Innovation Management. Palgrave Macmillan.

Arpaci, I. (2010). E-government and technological innovation in turkey. Transforming Government: People, Process and Policy,4(1), 37-53.

Austrian Standards Institute (2013). ONR CEN/TS 16555-1 Innovation Management - Part 1: Innovation Management System (prCEN/TS 16555-1:2012).

Retrieved 17 August 2015 from https://shop.austrian-standards.at/Preview.on;j sessionid $=$ E369CC54C56C37D243E14796B5CCF745 preview $=\&$ dokkey $=46$ $4571 \&$ selectedLocale $=$ en

Bagnoli, C., \& Vedovato, M. (2014). The impact of knowledge management and strategy configuration coherence on SME performance. Journal of Management \& Governance, 18(2), 615-647.

Belkhir, L. (2015). The Innovation Levers to Sustainable Management: Entrepreneurship, Design and Policy. Journal of Management and Sustainability, 5(1), 10-19. 
Bibo, L. (2014). Overtures to reducing Romanian Ministry of National Defense Tenuity in Information Resource Management. Journal of Defense Resources Management, 5(2), 89-98.

Brown, T. (2008). Design thinking. Harvard Business Review, June 2008, 84-92. Chih-Chang, C. (2013). The Free Cash Flow Rate on the Stock Return Rate. Journal of Accounting, Finance \& Management Strategy, 8(1), 1-22.

Choudhury, J. (2013). Documentation HR Configuration, Organisation Capital \& Bottom-Line: A Case of Indian IT Sector. Indian Journal of Commerce and Management Studies, 4(1), 38-42.

Cohendet, P., \& Simon, L. (2015). Introduction to the Special Issue on Creativity in Innovation. Technology Innovation Management Review, 5(7), 5-13.

Davidson, A., \& Leavy, B. (2007). Interview with innovation guru Geoffrey Moore: Seeking solutions to intractable problems. Strategy \& Leadership, 35(5), 4-8.

Deutsch, C. (2013). The seeking solutions approach: Solving challenging business problems with local open innovation. Technology Innovation Management Review, 3(3), 6-13.

Dougherty, D., \& Hardy, C. (1996). Sustained product innovation in large, mature organizations: Overcoming innovation-to-organization problems. Academy of Management Journal, 39(5), 1120-1153.

Dunne, D. \& Martin, R. (2006). Design Thinking and How It Will Change Management Education: An Interview and Discussion. Academy of Management Learning \& Education, 5(4), 512-523.

Euchner, J., \& Ganguly, A. (2014). Business Model Innovation in Practice: A systematic approach to business model innovation can help capture value and reduce risks. Research-Technology Management, November-December 2014, 33-39.

Frederic, T., Lam, T., \& Martin, V. (2014). A Lean Innovation Model to Help Organizations Leverage Innovation For Economic Value: A Proposal. International Journal of Management \& Information Systems, 18(2), 99-108.

Gibney, K. (1998). Awakening creativity. ASEE Prism, 7(7), 18-23.

Gil, A. M., Varela, G., \& González, A. (2008). Guía Práctica para la Implantación de la Norma "UNE 166002:2006 Gestión de la I+D+I: Requisitos del Sistema de Gestión de la I+D+I" en Empresas del Sector de la Edificación Residencial. Retrieved 17 August 2015 from https:/www.euskadi.eus/r41-18971/es/contenidos/ informacion/guia_innova/es_innova/adjuntos/tomo2cast.pdf

Gobble, M. M. (2014). Design Thinking. Research Technology Management, MayJune 2014, 59-61. Goldratt, E. (1997). Cadena Crítica. México: Ediciones Castillo. Goldratt, E. (1999). Programa Via Satélite de Goldratt: Manual del Participante. México: International Institute for Learning, Inc.

Grant, R. M. (2013). The development of knowledge management in the oil and gas Industry/El desarrollo de la dirección del conocimiento en la industria del petroleo y gas. Universia Business Review, 40(1), 92-125.

Iotti, M., \& Bonazzi, G. (2014). The application of life cycle cost (LCC) approach to quality food production: a comparative analysis in the Parma PDO Ham Sector. American Journal of Applied Sciences, 11(9), 1492-1506. 
ISO (2013).ISO/TC 279 Innovation management.

Retrieved 17 August 2015 from http://www.iso.org/iso/iso_technicalcommittee $\% 3$ Fcommid\%3D4587737

Kaski, T., Alamäki, A., \& Moisio, A. (2014). A Multi-Discipline Rapid Innovation Method. Interdisciplinary Studies Journal, 3(4), 163-170.

Klychova, G. S., Zakirova, A. R., Zakirov, Z. R., \& Valieva, G. R. (2015). Management Aspects of Production Cost Accounting in Horse Breeding. Asian Social Science, 11(11), 308-312.

Kousenidis, D. V. (2006). A free cash flow version of the cash flow statement: a note. Managerial Finance, 32(8), 645-663.

Laudon K. C., \& Laudon J. P. (2012). Management Information Sys t e $m s$ : Managing the Digital Firm (12th ed.). New Jersey, USA: Pearson Education.

Lugmayr, A., Stockleben, B., Zou, Y., Anzenhofer, S., \& Jalonen, M. (2014). Applying „design thinking“ in the context of media management education. Multimedia Tools and Applications, 71(1), 119-157.

Merfeld, D. (2014). GE Is in a Startup State of Mind. Research-Technology Management, November-December 2014, 26-31.

Mootee, I. (2013). Design thinking para la innovación estratégica: lo que no te pueden enseñar en las escuelas de negocio ni en las de diseño. Spain: Ediciones Urano.

Mûller-Prothmann, T., \& Stein, A. (2011). I2MM - Integrated Innovation Maturity Model for Lean Assessment of Innovation Capability. XXII ISPIM Conference 2011: Sustainability in Innovation.

Newfoundland Labrador. (n. d.). Governance of Evaluation, Proof of Concept and Pilot Projects. Retrieved from http:/www.ocio.gov.nl.ca/ocio/pmo/Governance Evaluations_POCs_Pilot.pdf

O`Raghallaigh, P., Sammon, D., \& Murphy, C. (2011). A re-conceptualisation of innovation models to support decision design. Journal of Decision Systems, 20(4), 361-382.

Pasian, B. (2014). Extending the concept and modularization of project management maturity with adaptable, human and customer factors. International Journal of Managing Projects in Business, 7(2), 186-214.

Pinho, I., Rego, A., \& Cunha, M. P. (2012). Improving knowledge management processes: A hybrid positive approach. Journal of Knowledge Management, 16(2), 215-242.

Project Management Institute. (2013). Project Management Body of Knowledge (5th ed.). Pennsylvania, USA: PMI Publications.

Raffai, C. (2013). Innovation in Rural Tourism: A Model for Hungarian Accommodation Providers. Management \& Marketing, 8(4), 747-766.

Rim, V. S. (2012). What is Design Thinking and Why Is It Important? Review of Educational Research, 82(3), 330-348.

Robinson, S., \& Stubberud, H. A. (2011). Problems in innovation: A Cross-Country Comparison. Washington, International Council for Small Business, 1-19.

Thabane, L., Ma, J., Chu, R., Cheng, J., Ismalia, A., Ríos, L. P., Robson, R., Thabane, 
M., Giangregorio, L., \& Goldsmith, C. H. (2010). A tutorial on pilot studies: the what, why and how. BMC Medical Research Methodology, 10(1), 1-10.

Van de Ven, A. H. (1986). Central problems in the management of innovation. Management Science, 32(5), 590.

\section{Author Note}

The author would like to thank the anonymous referees for their valuable feedback on the previous version of this manuscript.

Correspondence concerning this article should be addressed to Emigdio Alfaro, CENTRUM Católica Graduate Business School, PUCP, Calle Daniel Alomía Robles 125-129, Los Alamos de Monterrico, Santiago de Surco, Lima, Lima 33, Peru. Email: emigdio.alfaro@pucp.pe

\section{Biographical Note}

Emigdio Alfaro is a professor at CENTRUM Católica Graduate Business School, Pontificia Universidad Católica del Perú (PUCP), Lima, Peru. He is Doctor of Education from the Universidad Privada Norbert Wiener of Peru; Doctor (c) in Business Administration, MBA, and Master of Philosophy from the Maastricht School of Management, The Netherlands; Ph.D (c) in Strategic Management of Businesses and Master in Strategic Management from CENTRUM Católica Graduate Business School; and Informatics Engineer from PUCP. He has worked as manager, consultant, and auditor in diverse organizations from diverse sectors in strategic management, process management, project management, implementation of quality norms, and information technology management. 


\section{Appendix: Forms of the MIM3}

Table 2

FR-MIM3-001-001 Idea of Innovative Project

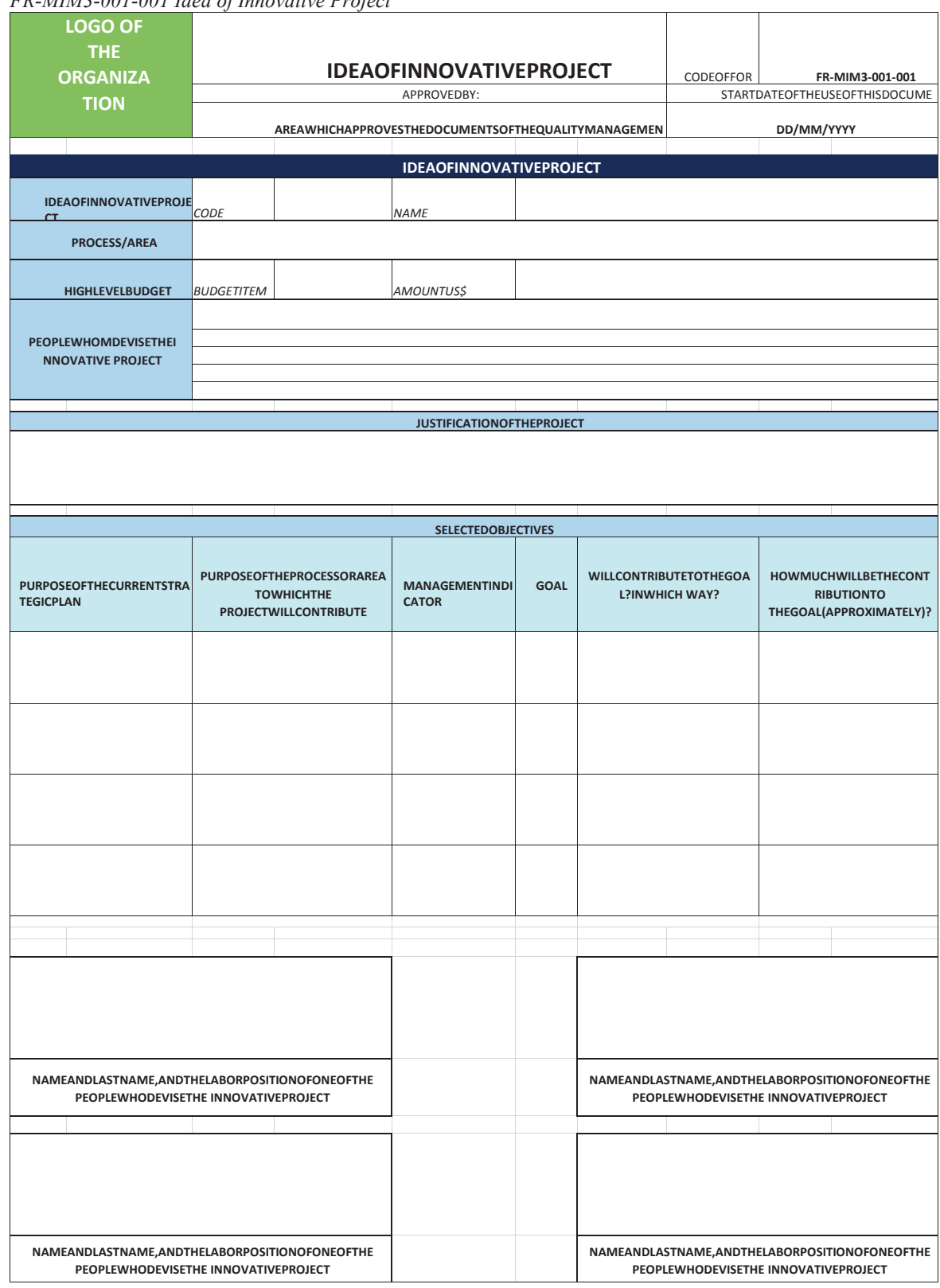


Table 3

FR-MIM3-002-001 Innovative Project Charter

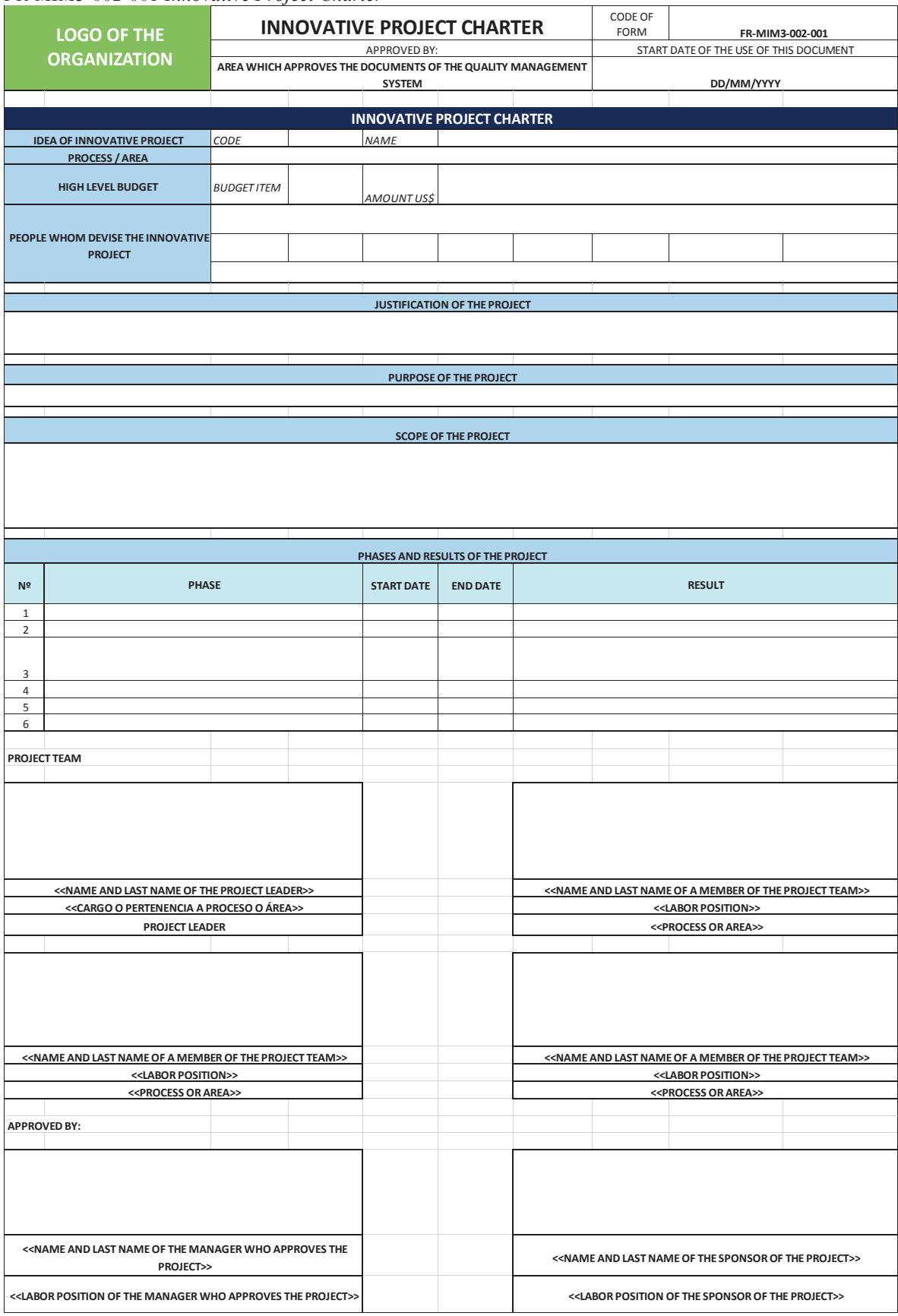


Table 4

FR-MIM3-003-001 Template of the Project Management Plan - Table of Contents

\section{TABLE OF CONTENTS}

1. PURPOSE

2. JUSTIFICATION

3. INTEGRATIONMANAGEMENT OF THE INNOVATIVE PROJECT $\ldots \ldots \ldots \ldots \ldots \ldots \ldots$

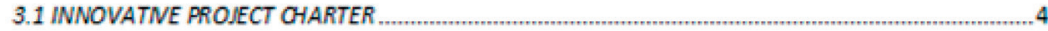

3.2 PROJECT CLOSURE.

3.3 INTEGRATED CONTROL OF CHANGES

4. SCOPE MANAGEMENT.

5. TIME MANAGEMENT

6. COSTMANAGEMENT

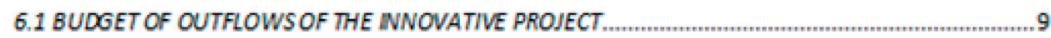

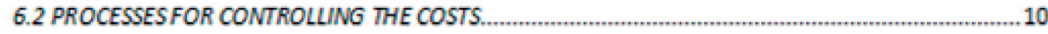

7. QUALITY MANAGEMENT

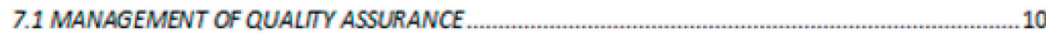

7.2 MANAGEMENT OF QUALTY CONTROL $\ldots \ldots$

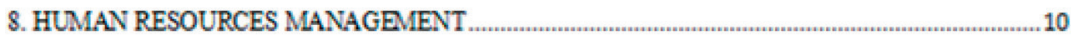

8.1 TEAM OF THE PROJECT.

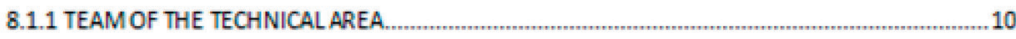

8.1.2 TEAMS OF OTHER AREAS

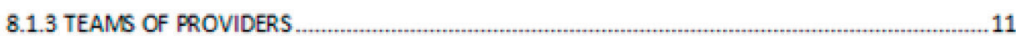

8.2 PROCESSES FOR MANAGING THE HUMAN RESOURCES

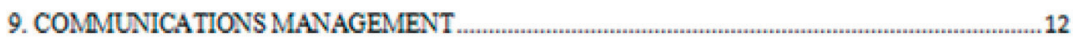

10. RISK MANAGEMENT

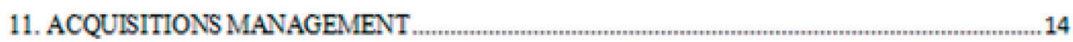

12. STAKEHOLDERS MANAGEMENT $\ldots \ldots$ 
Table 5

FR-MIM3-004-001 Technical Evaluation of the Project

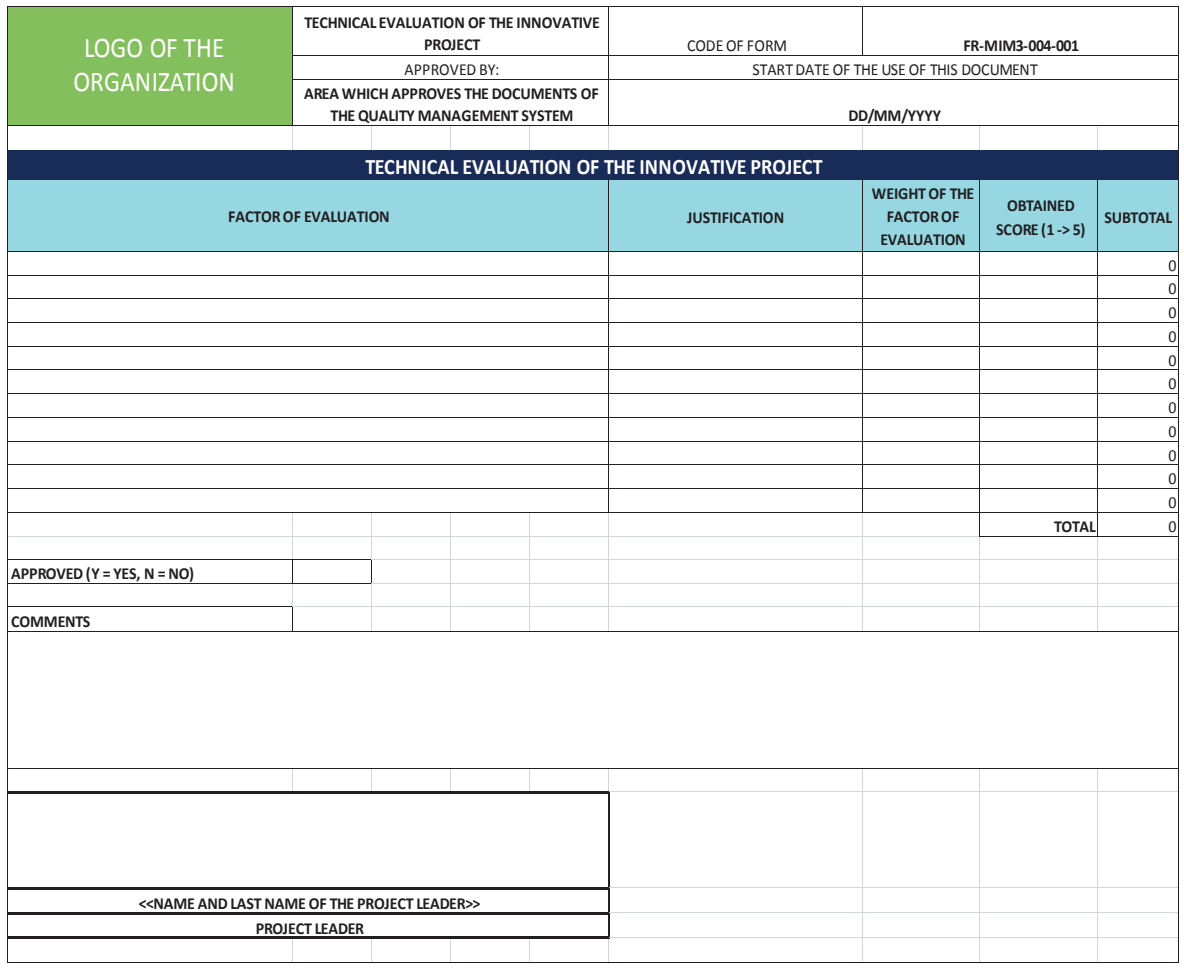


Table 6

FR-MIM3-005-001 Risks Management of the Innovative Project

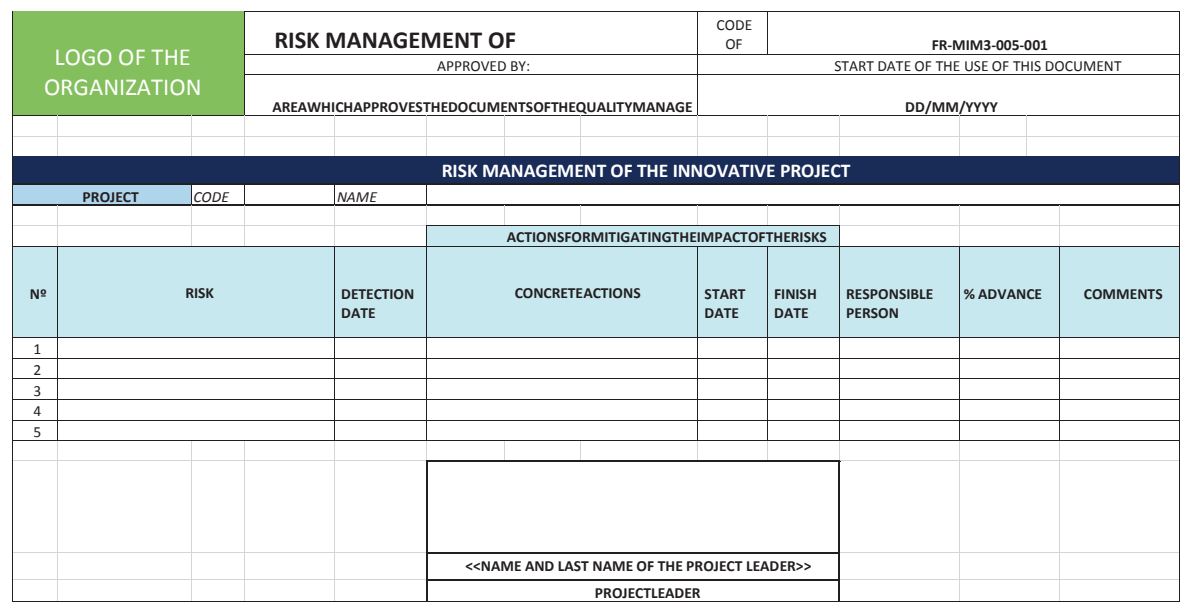


Table 7

FR-MIM3-006-001 Financial Evaluation of the Project

\begin{tabular}{|c|c|c|c|c|c|c|c|c|c|c|c|c|c|}
\hline \multirow{3}{*}{$\begin{array}{l}\text { LOGO OF THE } \\
\text { ORGANIZATION }\end{array}$} & \multicolumn{7}{|c|}{ FINANCIAL EVALUATION OF THE INNOVATIVE PROJECT } & $\begin{array}{c}\text { CODE OF } \\
\text { FORM }\end{array}$ & \multicolumn{5}{|c|}{ FR-MIM3-006-001 } \\
\hline & \multicolumn{7}{|c|}{ APPROVED BY: } & \multicolumn{6}{|c|}{ START DATE OF THE USE OF THIS DOCUMENT } \\
\hline & \multicolumn{7}{|c|}{$\begin{array}{l}\text { AREA WHICH APPROVES THE DOCUMENTS OF THE QUALTY } \\
\text { MANAGEMENT SYSTEM }\end{array}$} & \multicolumn{6}{|c|}{$\mathrm{DD} / \mathrm{MM} / \mathrm{YYYY}$} \\
\hline & \multicolumn{13}{|c|}{ FINANCIAL EVALUATION OF THE INNOVATIVE PROJECT } \\
\hline & Period 0 & Period 1 & Period 2 & Period 3 & Period 4 & Period 5 & Period 6 & Period 7 & Period 8 & Period 9 & 9 Period 10 & $\ldots$ & Period $\mathrm{N}$ \\
\hline \multicolumn{14}{|l|}{ ADDITIONALINFLOWS } \\
\hline \multicolumn{14}{|l|}{ Additional Inflows } \\
\hline \multirow{2}{*}{\multicolumn{14}{|c|}{ Savings }} \\
\hline & & & & & & & & & & & & & \\
\hline TOTAL & & 0 & 0 & 0 & 0 & 0 & 0 & 0 & 0 & 0 & 0 & 0 & 0 \\
\hline & & & & & & & & & & & & & \\
\hline \multicolumn{14}{|l|}{ ADDITIONAL OUTFLOWS } \\
\hline \multicolumn{14}{|l|}{ Additional Investments } \\
\hline \multicolumn{14}{|l|}{ Hardware Acquisition } \\
\hline & & & & & & & & & & & & & \\
\hline \multicolumn{14}{|l|}{ Software Acquisition } \\
\hline & & & & & & & & & & & & & \\
\hline \multicolumn{14}{|l|}{ Instalation } \\
\hline & & & & & & & & & & & & & \\
\hline \multicolumn{14}{|l|}{ Infrastructure } \\
\hline & & & & & & & & & & & & & \\
\hline Furniture and Equipment & & & & & & & & & & & & & \\
\hline & & & & & & & & & & & & & \\
\hline Additional Expenses & & & & & & & & & & & & & \\
\hline Personnel & & & & & & & & & & & & & \\
\hline & & & & & & & & & & & & & \\
\hline Advertising & & & & & & & & & & & & & \\
\hline & & & & & & & & & & & & & \\
\hline Training & & & & & & & & & & & & & \\
\hline & & & & & & & & & & & & & \\
\hline Support & & & & & & & & & & & & & \\
\hline & & & & & & & & & & & & & \\
\hline Maintenance & & & & & & & & & & & & & \\
\hline & & & & & & & & & & & & & \\
\hline Inactivated Time & & & & & & & & & & & & & \\
\hline & & & & & & & & & & & & & \\
\hline Space and Energy & & & & & & & & & & & & & \\
\hline & & & & & & & & & & & & & \\
\hline TOTAL & 0 & 0 & 0 & 0 & 0 & 0 & 0 & 0 & 0 & 0 & 0 & 0 & 0 \\
\hline NET FLOW & 0 & 0 & 0 & 0 & 0 & 0 & 0 & 0 & 0 & 0 & 0 & 0 & 0 \\
\hline & & & & & & & & & & & & & \\
\hline Discount rate & $0 \%$ & & Comments & & & & & & & & & & \\
\hline & & & & & & & & & & & & & \\
\hline NPV (Net Present Value) & 0 & & & & & & & & & & & & \\
\hline APPBOVED $(\mathrm{Y}=$ Yes $\mathrm{N}=\mathrm{N}$ ) & & & & & & & & & & & & & \\
\hline APPROVED ( $\mathrm{Y}=\mathrm{Yes}, \mathrm{N}=\mathrm{No}$ ) & & & & & & & & & & & & & \\
\hline & & & & & & & & & & & & & \\
\hline & & & & & & & & & & & & & \\
\hline & & & & & & & & & & & & & \\
\hline$<<$ NAME AND LASTN & F THE PROJ & JJECT LEADE & & & & & & & & & & & \\
\hline & LEADER & & & & & & & & & & & & \\
\hline
\end{tabular}


Table 8

FR-MIM3-007-001 Registration of Innovative Project's Learned Lessons

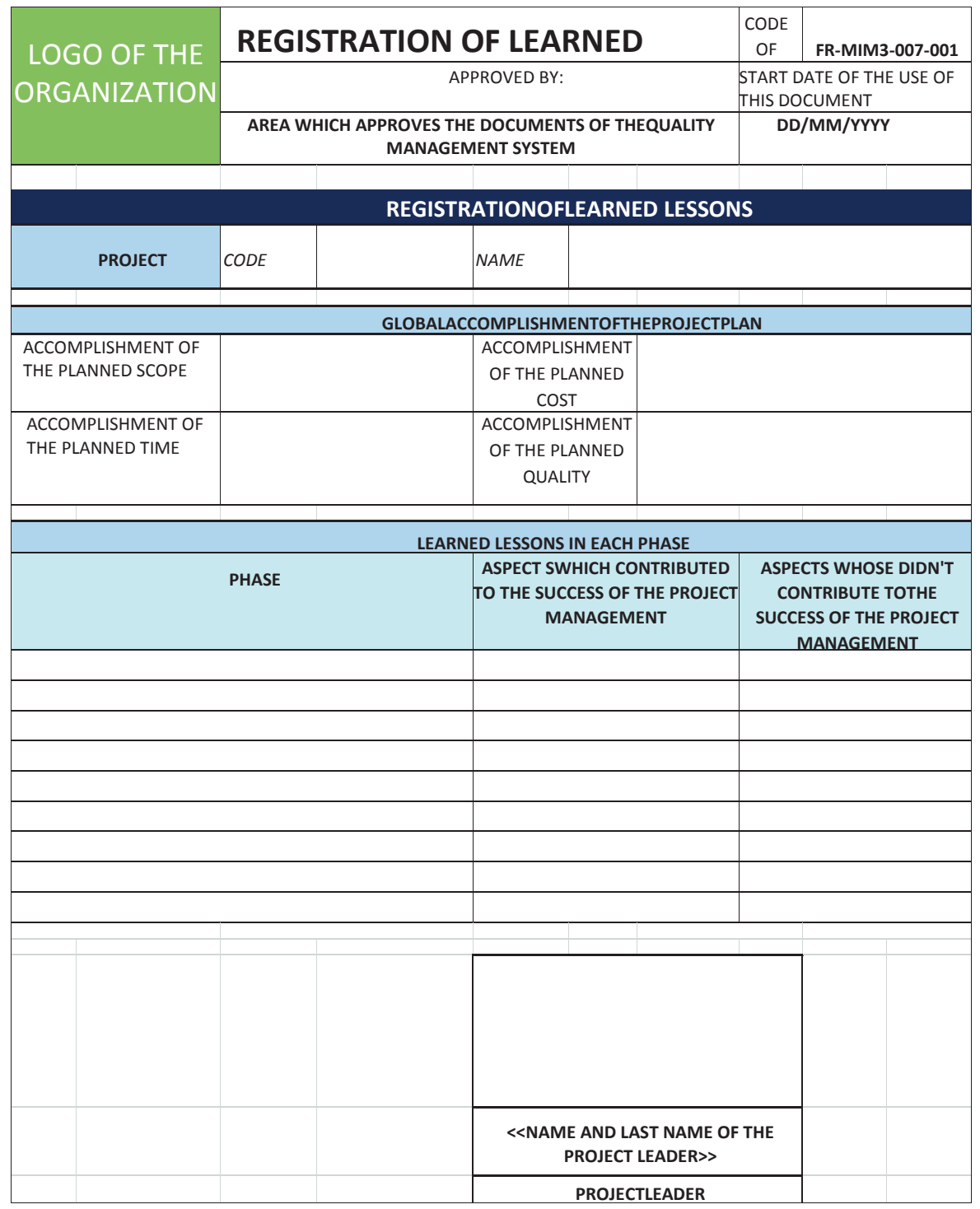


Table 9

FR-MIM3-008-001 Form of Project Closure

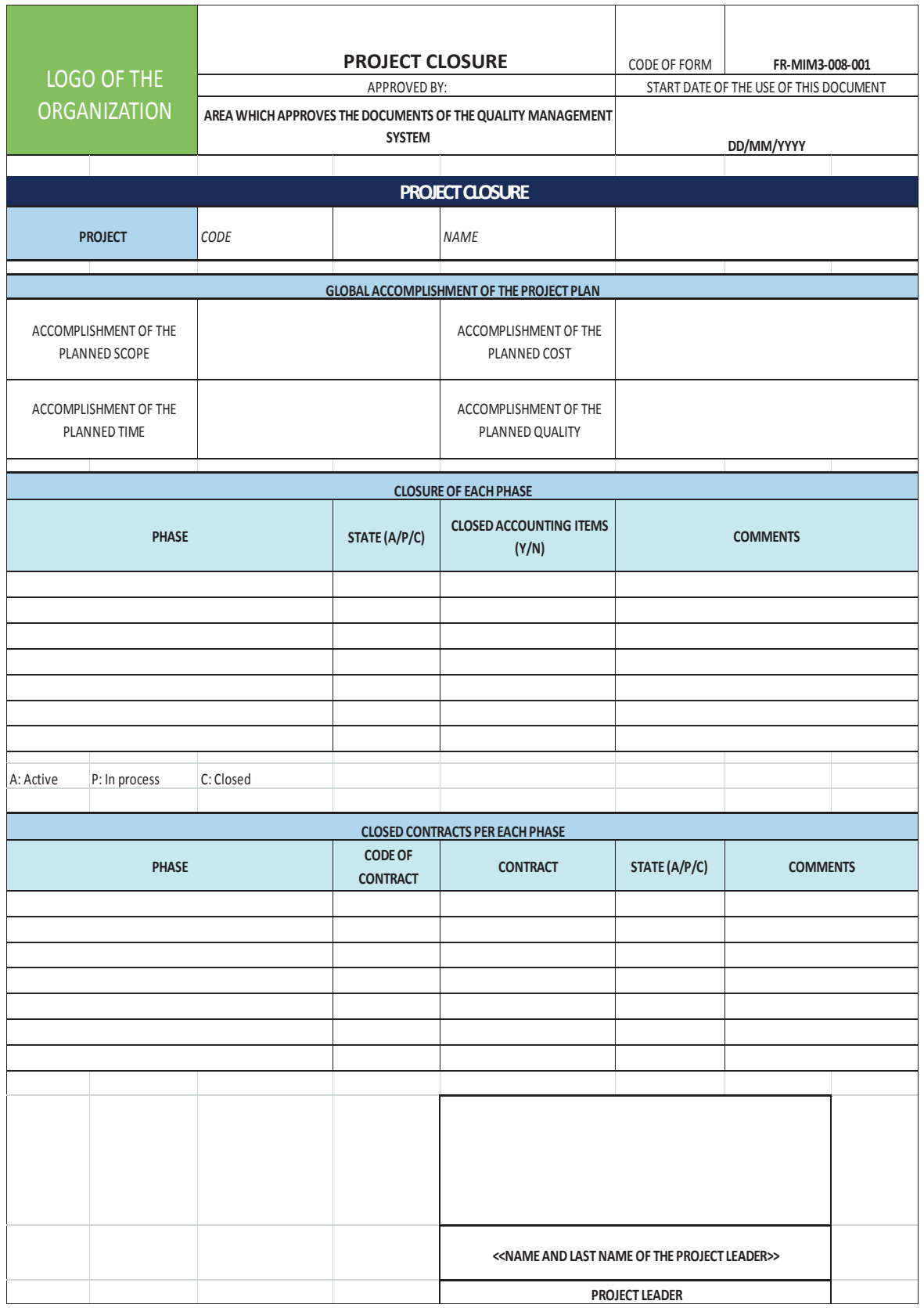


Table 10

FR-MIM3-009-001 Budget of Outflows of the Innovative Project

\begin{tabular}{|l|c|c|c|}
\hline \multirow{3}{*}{ LOGO OF THE ORGANIZATION } & BUDGET OF INNOVATIVE PROJECT'S OUTFLOWS & $\begin{array}{c}\text { CODE OF } \\
\text { FORM }\end{array}$ & FR-MIM3-009-001 \\
\cline { 2 - 3 } & APPROVED BY: & START DATE OF THE USE OF THIS DOCUMENT \\
\cline { 2 - 3 } & AREA WHICH APPROVES THE DOCUMENTS OF THE QUALITY MANAGEMENT SYSTEM & DD/MM/YYYY \\
\hline
\end{tabular}

\begin{tabular}{|c|c|c|c|c|c|c|c|c|c|c|c|c|c|c|c|c|c|c|c|}
\hline \multicolumn{20}{|c|}{ BUDGET OF INNOVATIVE PROJECT'S OUTFLOWS } \\
\hline & \multirow{2}{*}{\multicolumn{7}{|c|}{ Year 1}} & \multirow{2}{*}{\multicolumn{12}{|c|}{ Year 2}} \\
\hline TYPE OF OUTFLOW & Jun & & & & & & & Jan & $\mathrm{Feb}$ & Mar & Apr & May & Jun & Jul & Aug & & & & Dec \\
\hline \multicolumn{20}{|l|}{ ADDITIONAL INVESTMENTS } \\
\hline & & & & & & & & & & & & & & & & & & & \\
\hline & & & & & & & & & & & & & & & & & & & \\
\hline & & & & & & & & & & & & & & & & & & & \\
\hline & & & & & & & & & & & & & & & & & & & \\
\hline & & & & & & & & & & & & & & & & & & & \\
\hline \multirow{2}{*}{\multicolumn{20}{|c|}{ ADDITIONAL EXPENSES }} \\
\hline & & & & & & & & & & & & & & & & & & & \\
\hline & & & & & & & & & & & & & & & & & & & \\
\hline & & & & & & & & & & & & & & & & & & & \\
\hline & & & & & & & & & & & & & & & & & & & \\
\hline & & & & & & & & & & & & & & & & & & & \\
\hline & & & & & & & & & & & & & & & & & & & \\
\hline & & & & AMEA & NDLAS & TNAM & IEOFT & HEPRO. & JECTLE & EADER> & & & & & & & & & \\
\hline & & & & & & PROJE & CTLEA & & & & & & & & & & & & \\
\hline
\end{tabular}


Table 11

FR-MIM3-010-001 Schedule of the Project

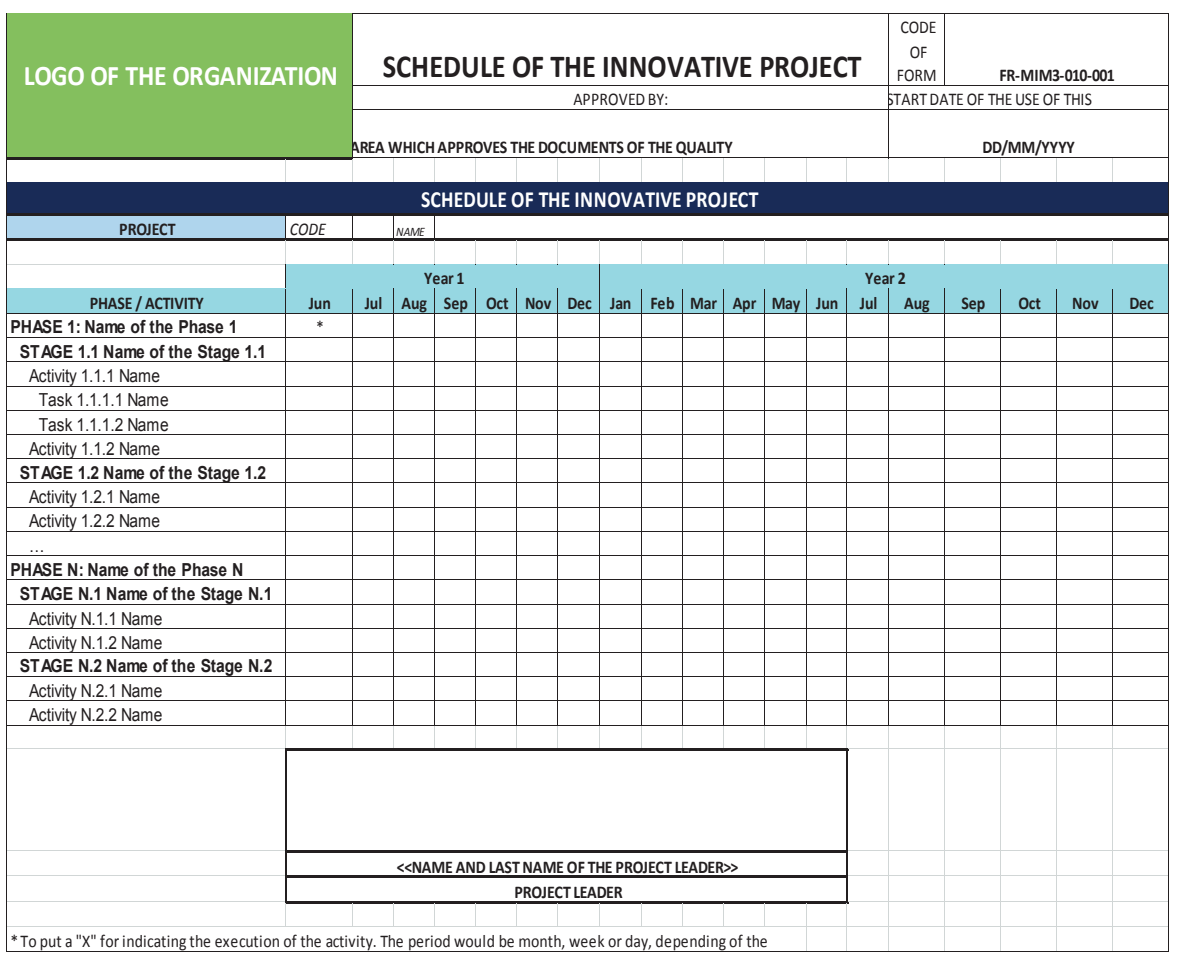


Table 12

FR-MIM3-011-001 Control of Changes of the Innovative Project

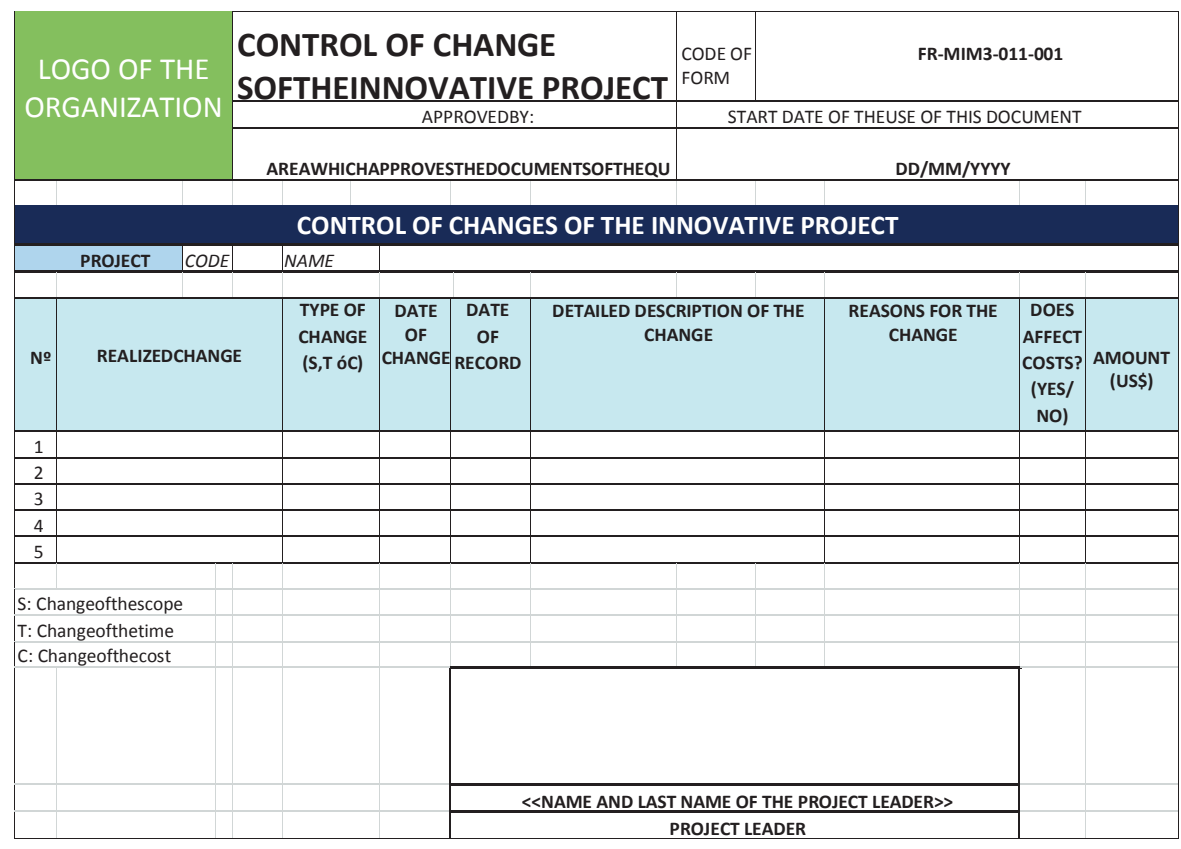


Table 13

FR-MIM3-012-001 Communications Management of the Innovative Project

\begin{tabular}{|c|l|l|c|}
\hline \multirow{2}{*}{$\begin{array}{c}\text { LOGO OF THE } \\
\text { ORGANIZATION }\end{array}$} & $\begin{array}{l}\text { COMMUNICATIONS } \\
\text { MANAGEMENT OFTHE } \\
\text { INNOVATIVE PROJECT }\end{array}$ & $\begin{array}{l}\text { OF } \\
\text { FORM }\end{array}$ & FR-MIM3-012-001 \\
\cline { 2 - 4 } & APPROVED BY: & START DATE OF THE USE OF THIS DOCUMENT \\
\cline { 2 - 4 } & $\begin{array}{c}\text { AREA WHICH APPROVES THE DOCUMENTS } \\
\text { OF THE QUALITY MANAGEMENT SYSTEM }\end{array}$ & & DD/MM/YYYY \\
\hline
\end{tabular}

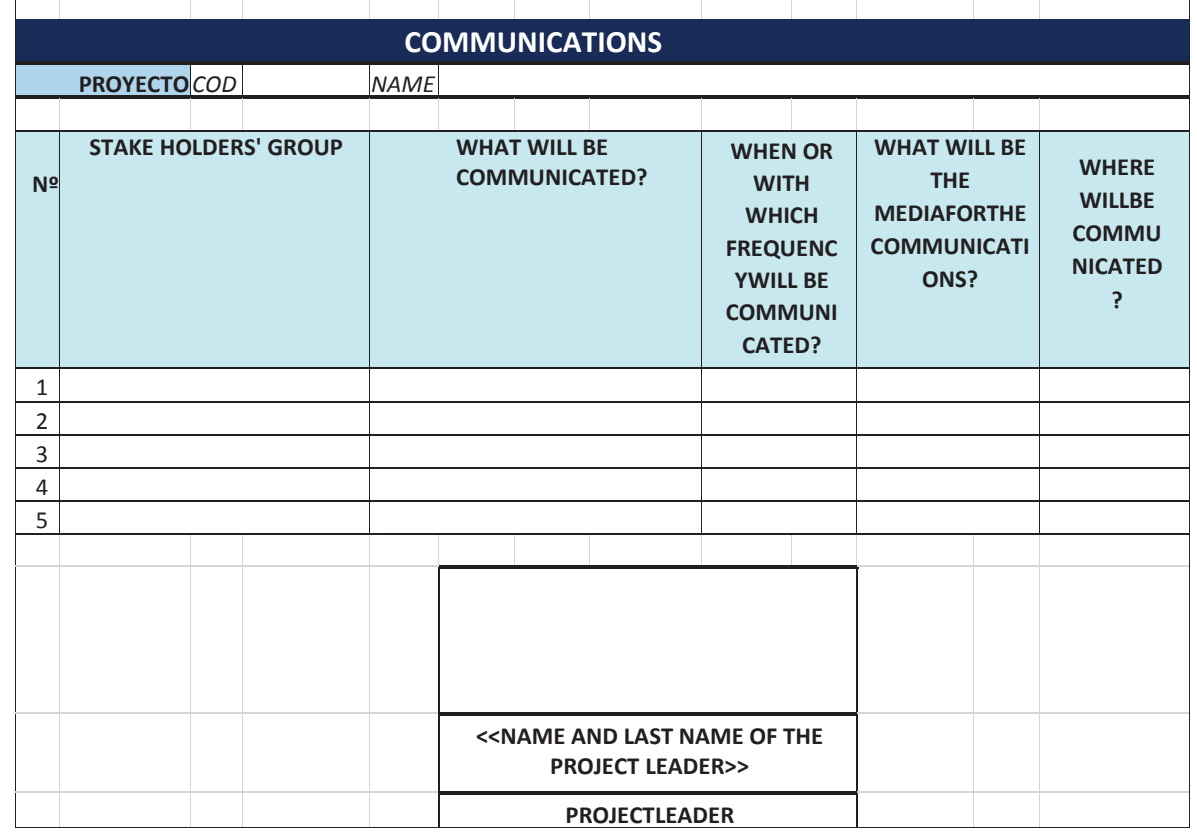


Table 14

FR-MIM3-013-001 Yellow Pages of the Project

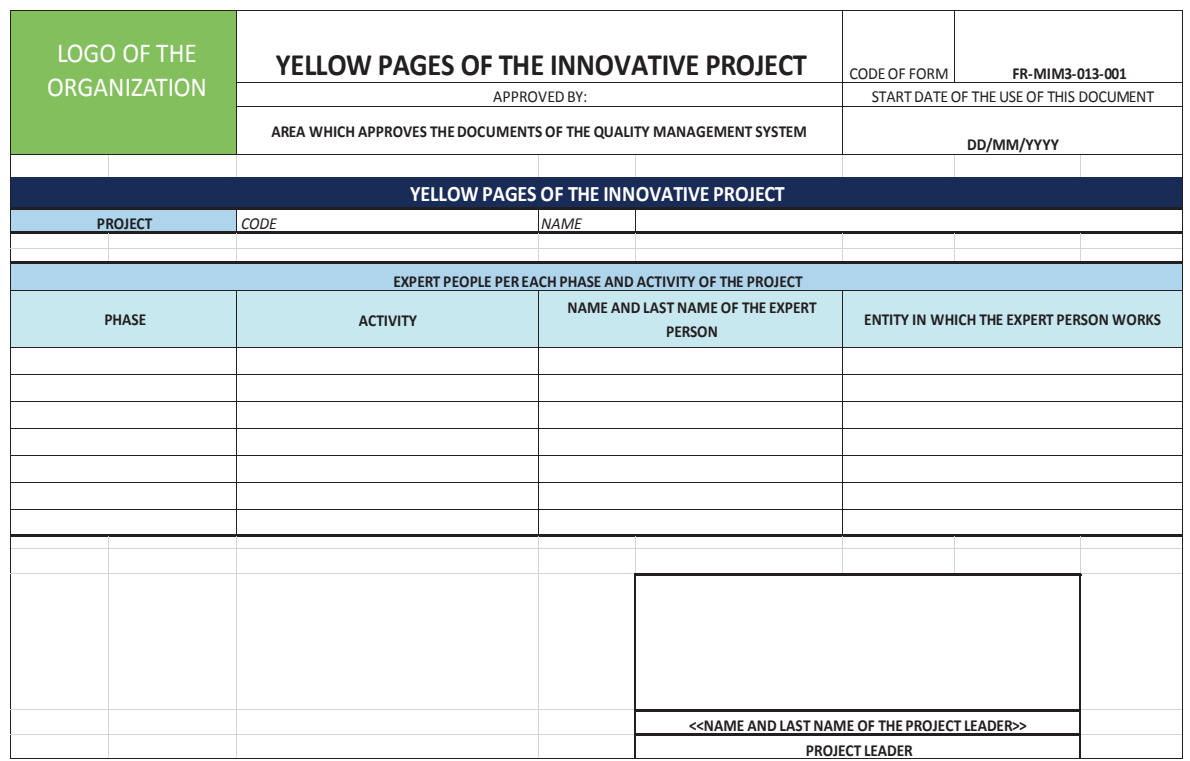

